\title{
Balancing the struggle to live with dementia: a systematic meta-synthesis of coping
}

\author{
Guro Hanevold Bjørkløf', Anne-Sofie Helvik ${ }^{1,2}$, Tanja Louise Ibsen', Elisabeth Wiken Telenius ${ }^{1}$,
} Ellen Karine Grov ${ }^{3}$ and Siren Eriksen ${ }^{1,4^{*}}$ (D)

\begin{abstract}
Background: People with dementia describe experiences of loss that threaten their autonomy and ability to contribute to society. They often have difficulties with orientation, loss of roll function, and fear about the future, and need help from others. An increasing body of literature also focuses on how people with dementia search for meaning and maintaining of quality to life, and how they find strategies to live with dementia. A review of the scientific literature on coping and dementia is warranted and can help to advice and inform healthcare personnel and decision makers on how they can support and plan for appropriate healthcare services for people with dementia. The aim of this systematic meta-synthesis was therefore to interpret and synthesize knowledge regarding people with dementia's experience of coping.
\end{abstract}

Methods: We conducted a systematic, computerised search of Medline, Embase, Cinahl Complete, PsycINFO and Age Line combining MeSH terms and text words for different types of dementia with different descriptions of experience. Studies comprised 1) a sample of people with dementia, 2) a qualitative interview as a research method and 3) a description of experiences of coping were included. The search resulted in 7129 articles, of which 163 were read in full text, 80 were excluded due to the exclusion criteria or low quality according. The analysis was conducted in line with qualitative content analyses.

Results: This interpretative qualitative meta-synthesis included 74 articles of good quality encompassing interviews with 955 persons with dementia. The material revealed two main resources of coping: (1) Humour and (2) Practical and emotional support, and four overall strategies in which people with dementia cope with the challenges they experience: (1) Keep going and holding on to life as usual; (2) Adapting and adjusting to the demands from the situation; (3) Accepting the situation; and (4) Avoiding the situation A comprehensive understanding of the categories led to the latent theme: Balancing the struggle of living with dementia.

Conclusion: This meta-synthesis indicates that people with dementia cope in different ways and using several parallel strategies. This insight is essential in dementia care to facilitate a supportive environment.

Keywords: Dementia, Meta-synthesis, Interviews, Coping, Life world perspective, Person's experiences

\footnotetext{
* Correspondence: siren.eriksen@aldringoghelse.no

${ }^{1}$ Norwegian National Advisory Unit on Ageing and Health (Ageing and

Health), Postbox 2136, N-3103 Tønsberg, Norway

${ }^{4}$ VID Spesialized University, Faculty of Health Studies, Oslo, Norway

Full list of author information is available at the end of the article
}

(c) The Author(s). 2019 Open Access This article is distributed under the terms of the Creative Commons Attribution 4.0 International License (http://creativecommons.org/licenses/by/4.0/), which permits unrestricted use, distribution, and reproduction in any medium, provided you give appropriate credit to the original author(s) and the source, provide a link to the Creative Commons license, and indicate if changes were made. The Creative Commons Public Domain Dedication waiver (http://creativecommons.org/publicdomain/zero/1.0/) applies to the data made available in this article, unless otherwise stated. 


\section{Background}

Dementia is a common term for a chronic functional decline caused by disease or damage in the brain, where Alzheimer's disease is the most common [1, 2]. During progression of this decline the need for help from others are unavoidable and the focus moves from maintenance of daily functioning and activities in early phase towards comfort and well-being in late stage [3]. In the late, severe stage of dementia, the patients will be fully dependent on others and patients will eventually die [2, 4]. According to Alzheimer's Disease International [5], the World Health Organization [6] and the Norwegian Dementia Plan 2020 [7], dementia treatment and care need to be based on the values of person-centered care [8]. Thus, in providing the appropriate treatment and support in accordance to people with dementia's own needs and fundamental human rights, knowledge about how people with dementia experience and cope with their current and future lifesituation is fundamental.

To live with dementia is an idiosyncratic experience as dementia influence each individual differently. Thus, a person becoming ill with a dementia will in different ways become dependent on own and surrounding resources for coping as the illness progresses. The concept 'coping' refers to the struggle to overcome and manage the stress from adapting in life [9]. Coping strategies are defined as "cognitive and behavioural efforts to master, reduce, or tolerate the internal and/ or external demands that are created by the stressful transaction" (p.843) [10]. Folkman \& Lazarus' transactional perspective on coping highlights people and surrounding environment to be in an ongoing reciprocal relationship. Life-stressors are constantly being evaluated in a process of appraisals where perceptions of available internal and external resources (primary appraisals) affect choice of strategies used to cope with the situation (secondary appraisal) [11]. The strategies involve approaches aiming to alter the stressful situation (i.e. problem-focused coping strategies), as well as regulation of emotional distress associated with the situation (i.e. emotion-focused coping strategies) $[11,12]$. Thus, the strategies for coping depend on appraisals of the situational context and of personal factors; altogether constituting the individual's available coping resources $[11,13]$. Normally, people alternate between problem- and emotional-focused coping strategies, but in more severe and acute stress the use of all available strategies is triggered in a global coping response [11, 1417]. A global coping response is defined as a response in acute and severe stress where you use: "combinations of almost all of the problem-focused and emotion-focused coping strategies, indicating the use of a substantial global coping response" ([17]p., 949).

During the last decade, a growing body of research has emerged that focus on how people experience and cope with dementia [18-20]. A review of the scientific literature on coping and dementia is therefore warranted and can help to advice and inform healthcare personnel, decision makers and informal carers on how they can support and plan for appropriate healthcare services for people with dementia.

\section{The review \\ Design}

An interpretative qualitative meta-synthesis was conducted [21, 22]. The review includes cross-sectional and longitudinal qualitative interview-studies describing coping in different ways.

\section{Methods}

The methodology used for this meta-synthesis has also been used by some of the authors in previous published work [23, 24]. We conducted a systematic search combining different words for dementia and experience. The search was conducted in five databases: Age Line, Cinahl Complete, Embase, Medline and PsycINFO. See Table 1 for an overview of the search strategy as a whole. The search was restricted to peer-reviewed qualitative research studies in English language published between January 2004 and June 2018. We identified 7129 articles, of which 163 qualified for inclusion. Details of the inclusion og exclusion process is described in flowchart, Fig. 1.

To minimize the risk of mistakes and ensure consistency in quality, the screening of articles was performed by pairs of authors, in line with PRISMA standard [25]. Disagreements was resolved by discussions in the whole group. Potential articles were read in full text and included if: (1) the sample consisted of people with dementia only; (2) the research method was qualitative interview; (3) the voice of people with dementia was clearly described; and (4) the article included a description of experiences of coping. Articles were excluded if: (1) dementia was described as probable or possible; (2) there was a mixed sample with people with dementia and people with other diagnoses, and (3) the paper described experience from a specific intervention.

\section{Assessment of the quality of the studies}

Eighty-three of the articles were reviewed according to the CASP (Critical Appraisal Skills Programme) criteria for qualitative studies [26]. The quality of the studies was also assessed by pairs of authors. If disagreement that could not be resolved by discussion occurred, the group involved one of the other authors. We used the following nine criteria of the CASP: (1) a clear statement of aims; (2) appropriate choice of the method; (3) appropriate research design; (4) congruence between the recruitment strategy, aims and research; (5) the data collection method addresses the research issue; (6) a relationship between the researcher and the participant was considered; (7) ethical issues were considered; (8) the process of data analysis 
Table 1 Search terms

\begin{tabular}{ll}
\hline Dementia & Experience \\
\hline AGELINE & AGELINE \\
Dement* OR Presenile dement* OR Senile dement* OR & [Personal experience* OR Experience* OR Lived experience* \\
Alzheimer* OR Multi-infarct dement* OR Lewy Body & OR Life experience* OR Patient experience* OR Subjective \\
dement* OR Vascular dement* OR Frontotemporal $^{*}$ & experience* OR First-person] TX \\
dement*] TX [all text] & AND [nursing methodologies OR case study OR constant \\
OR [dementia OR alzheimers disease OR alzheimers* & comparison OR content analysis OR descriptive study OR \\
OR lewy body*] SU [Subject] & discourse analysis OR ethnography OR exploratory OR \\
& feminist OR grounded theory OR hermeneutic OR interview \\
& OR narrative OR naturalistic OR participant observation OR \\
& phenomenology OR qualitative research OR qualitative \\
CINAHL & methods OR qualitative study] \\
[Dementia OR Dementia, presenile OR Dementia, senile & CINAHL \\
OR Alzheimer's disease OR Dementia, multi-infarct OR & [Life N1 Experience] OR [Personal experience* OR Experience* \\
Lewy Body Disease OR Dementia, vascular] MESH & OR Lived experience* OR Life experience* OR Patient experience* \\
OR [Dement* OR Presenile dement* OR Senile dement* & OR Subjective experience* OR First-person] TX
\end{tabular}

OR [Dement* OR Presenile dement* OR Senile dement* OR Alzheimer* OR Multi-infarct dement* OR Lewy Body dement* OR Vascular dement* OR Frontotemporal dement*] TX [all text]

\section{EMBASE}

[Dementia OR Dementia, presenile OR Dementia, senile OR Alzheimer's disease OR Dementia, multi-infarct OR Lewy Body Disease OR Dementia, vascular OR Dementia, frontotemporal] Keyword [KW]

OR [Dement* OR Presenile dement* OR Senile dement* OR Alzheimer* OR Multi-infarct dement* OR Lewy Body dement* OR Vascular dement* OR Frontotemporal dement*] TW

\section{MEDLINE}

[Dementia OR Dementia, presenile OR Dementia, senile OR Alzheimer's disease OR Dementia, multi-infarct OR Lewy Body Disease OR Dementia, vascular] MESH OR [Dement* OR Presenile dement* OR Senile dement* OR Alzheimer* OR Multi-infarct dement* OR Lewy Body dement* OR Vascular dement* OR Frontotemporal dement*] TW

\section{PSYCHINFO}

[Dementia OR Dementia, presenile OR Dementia, senile OR Alzheimer's disease OR Dementia, multi-infarct OR Lewy Body Disease OR Dementia, vascular] MESH OR [Dement* OR Presenile dement* OR Senile dement* OR Alzheimer* OR Multi-infarct dement* OR Lewy Body dement* OR Vascular dement* OR Frontotemporal dement* Tw
EMBASE:

[Personal experience* OR Experience* OR Lived experience* OR Life experience* OR Patient experience* OR Subjective experience* OR First-person] TW was sufficiently rigorous; and (9) a clear statement of the findings. Each criterion was given an equal weight (i.e., 1 point) for a maximum score of nine for each quality assessment per article. We considered a score of nine as high methodological quality and a score of 7-8 points was considered moderate quality (see Table 2). We included studies with a moderate or high quality. Nine studies were excluded due to low quality and scores below 7 .

We included a total of 74 articles interviewing 995 people with dementia in the meta-synthesis. The studies are presented in Table 3. Fifty-three of the articles emphasized on the participants' ability to provide informed consent and verbally articulate their experiences, but only 21 described the participants' stage of dementia or level of cognitive function. However, all studies provided information about participants' housing situation and relocation to long-term care can serve as an indicator of dementia being in a moderate to severe stage. Among the included studies,13 studies interviewed participants living in nursing homes or other care facilities, 57 studies included participants living at home, and 4 studies had a mixed sample. Individual interviews constituted the main data and were described in 64 of the studies. Four studies were based on interviews with dyads or pairs consisting of person with dementia and health care personnel, and six studies were based on focus group interviews including people with dementia. Most studies conducted single interviews with the participants, but 17 studies were based on repeated interviews and of those, nine studies carried out interviews over a 


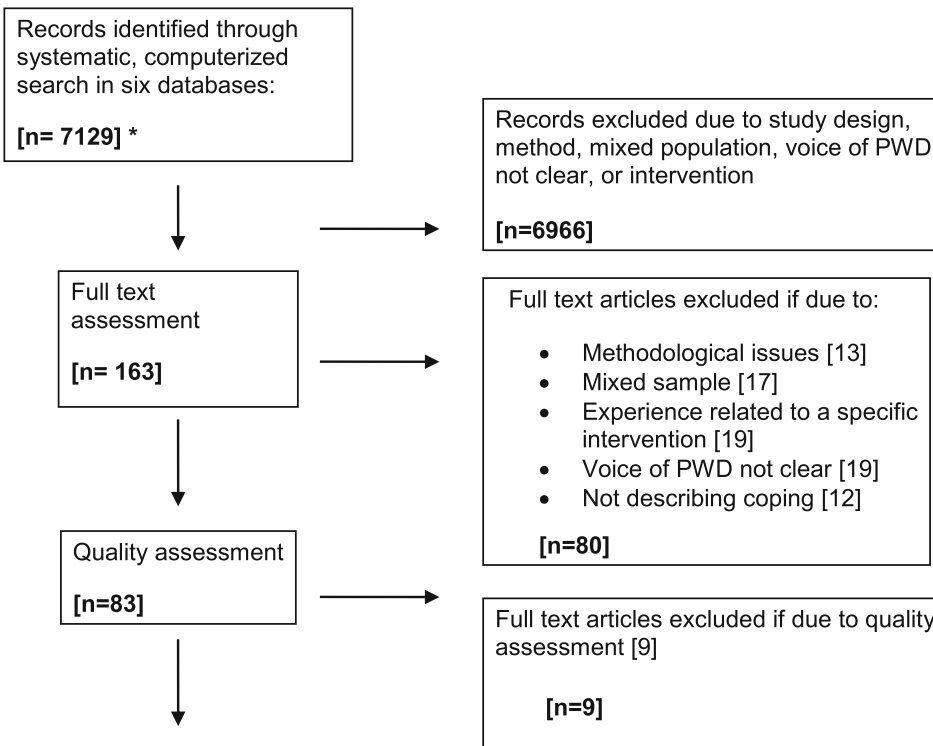

Qualitative studies included in the meta-synthesis $[\mathrm{n}=74]$

Fig. 1 Flow chart, literature search

period of more than 2 months and can be characterized as longitudinal studies.

\section{Data abstraction and synthesis}

The abstraction and synthesis were conducted according to the principles of the interpretative synthesis [99]. We focused on the development of concepts based on the data from primary studies and further developed and specified theories that integrated the concepts [100]. The analysis built on the principles of qualitative content analyses [101] and comprised six steps: In the first step, pairs of authors (TLI, EKG, EWT and SE) read all the 74 papers. Results from the papers describing coping, were extracted as direct citations into "meaning units" (TLI and SE); a form created for further analysis [101]. In the second step, two of the authors (TLI and SE) condensed the meaning units. This is a process were the content of the direct citation is being extracted using the meaning unit's own language. In the third step, two other authors (GHB and ASH) labelled the condensed meaning units with codes in order to organize the material. In the fourth step all authors compared codes and identified similarities and differences in order to structure and gathering the codes into subcategories. In the fifth step, the eight subcategories identified through this process were ultimately gathered into four categories with subcategories presenting the manifest meaning of the material. Finally, in the sixth step, the comprehensive understanding phase, we summarized and reflected upon the results consisting of resources and strategies, in order to reach a presentation of the text as one overall latent theme [101].

\section{Results}

The 74 articles included in this meta-synthesis described challenges and sources of stress that people with dementia encounters. The studies reported experience of loss of autonomy, control and connection. The participants see themselves as "different" and no longer normal [32]. The memory problems, other symptoms of dementia and the unpredictable progression of the disease lead to worry and anxiety. The participants experience that their needs change; the need to be looked after and to be taken care of increases, and furthermore, new social and emotional needs arise [36]. The studies describe the experience of being stigmatized, feeling embarrassed or stupid. Dementia threatens the identity and sense of worth and changes their roles and the relationship to others $[30,50]$. The participants state that taking part in social events and meaningful activities become more difficult. Consequently, some feel that they lack competency and may not be contributing as much as they would like, for instance in household and society. Loss of social contact and meaningful activities lead to loneliness, isolation, emptiness or boredom and many people experience that it is necessary to adjust life expectations $[50,89]$. The decline in function and abilities have great 
Table 2 Quality assessment of studies included

\begin{tabular}{|c|c|c|c|c|c|c|c|c|c|c|c|}
\hline \multirow[t]{2}{*}{ Study } & \multicolumn{9}{|c|}{ Criteria $^{a}$} & \multirow[t]{2}{*}{ Total /9 } & \multirow[t]{2}{*}{ Quality } \\
\hline & 1 & 2 & 3 & 4 & 5 & 6 & 7 & 8 & 9 & & \\
\hline Aldridge $\mathrm{H}$ et al. 2017 [27] & + & + & + & + & + & - & + & + & + & 8 & Moderate \\
\hline Aminzadeh F et al. 2009 [28] & + & + & + & + & + & - & + & + & + & 8 & Moderate \\
\hline Aminzadeh F et al. 2010 [29] & + & + & + & + & + & - & - & + & + & 7 & Moderate \\
\hline Atta-Konadu E et al. 2011 [30] & + & + & + & + & + & - & - & + & + & 7 & Moderate \\
\hline Barrett C and Crameri P 2015 [31] & + & + & + & - & +- & - & + & + & + & 7 & Moderate \\
\hline Beattie et al. 2004 [32] & + & + & + & + & + & - & + & + & + & 8 & Moderate \\
\hline Borley G and Hardy S 2017 [33] & + & + & + & + & + & - & + & + & + & 8 & Moderate \\
\hline Bronner K et al. 2016 [34] & + & + & + & + & + & - & - & + & + & 7 & Moderate \\
\hline Brorsson et al. 2011 [35] & + & + & + & + & + & - & + & + & + & 8 & Moderate \\
\hline Chaplin R et al. 2016 [36] & + & + & + & + & + & - & + & + & + & 8 & Moderate \\
\hline Clare L et al. 2008 [37] & + & + & + & + & + & - & + & + & + & 8 & Moderate \\
\hline Clemerson G et al. 2014 [38] & + & + & + & + & + & - & + & + & + & 8 & Moderate \\
\hline Dalby P et al. 2012 [39] & + & + & + & + & + & + & + & + & + & 9 & High \\
\hline Derksen E et al. 2006 [40] & + & + & + & + & + & - & + & + & + & 8 & Moderate \\
\hline De Witt 2009 [41] & + & + & + & + & + & - & + & + & + & 8 & Moderate \\
\hline De Witt 2010 [42] & + & + & + & + & + & - & + & + & + & 8 & Moderate \\
\hline Digby 2011 [43] & + & + & + & + & + & + & + & - & + & 8 & Moderate \\
\hline Digby 2012 [44] & + & + & + & + & + & + & + & + & + & 9 & High \\
\hline Duggan et al. 2008 [45] & + & + & + & + & + & - & + & - & + & 7 & Moderate \\
\hline Fleming R et al. 2015 [46] & + & + & + & + & + & + & + & + & + & 9 & High \\
\hline Frazer SM et al. 2011 [47] & + & + & + & + & + & - & + & + & + & 8 & Moderate \\
\hline Genoe MR et al. 2010 [48] & + & + & + & + & + & - & + & + & + & 8 & Moderate \\
\hline Genoe MR et al. 2012 [49] & + & + & + & + & + & - & + & + & + & 8 & Moderate \\
\hline Genoe MR and Dupuis SL 2014 [50] & + & + & + & + & + & + & + & + & + & 9 & High \\
\hline Gill L et al. 2011 [51] & + & + & + & + & + & - & + & + & + & 8 & Moderate \\
\hline Gilmour JA and Huntington AD 2005 [52] & + & + & + & + & + & - & + & + & + & 8 & Moderate \\
\hline Goodman C et al. 2013 [53] & + & + & + & + & + & - & + & + & + & 8 & Moderate \\
\hline Hain D et al. 2014 [54] & + & + & + & - & + & - & + & + & + & 7 & Moderate \\
\hline Harman G and Clare L 2006 [55] & + & + & + & + & + & + & + & + & + & 9 & High \\
\hline Harris PB 2011 [56] & + & + & + & + & + & - & + & + & + & 8 & Moderate \\
\hline Hedman R et al. 2013 [57] & + & + & + & + & + & - & + & + & + & 8 & Moderate \\
\hline Hedman R et al. 2016 [58] & + & + & + & + & + & + & + & + & + & 9 & High \\
\hline Heggestad A et al. 2013 [59] & + & + & + & + & + & + & + & + & + & 9 & High \\
\hline Hellström I et al. 2015 [60] & + & + & + & - & + & - & + & + & + & 7 & Moderate \\
\hline Herron RV and Rosenberg MW 2017 [61] & + & + & + & - & + & - & + & + & + & 7 & Moderate \\
\hline Hillmann A et al. 2018 [62] & + & + & + & - & + & - & + & + & + & 7 & Moderate \\
\hline Hulko W 2009 [63] & + & + & + & + & + & - & + & + & + & 8 & Moderate \\
\hline Johannessen A et al. 2011 [64] & + & + & + & + & + & - & + & + & + & 8 & Moderate \\
\hline Johannessen A et al. 2014 [65] & + & + & + & + & +- & - & + & + & + & 8 & Moderate \\
\hline Karlsson E et al. 2014 [66] & + & + & + & + & + & - & + & + & + & 8 & Moderate \\
\hline Keller HH et al. 2010 [67] & + & + & + & + & + & + & - & + & + & 8 & Moderate \\
\hline Langdon SA et al. 2007 [68] & + & + & + & + & + & + & + & + & + & 9 & High \\
\hline Lawrence RM et al. 2009 [69] & + & + & + & + & + & + & + & + & + & 9 & High \\
\hline
\end{tabular}


Table 2 Quality assessment of studies included (Continued)

\begin{tabular}{|c|c|c|c|c|c|c|c|c|c|c|c|}
\hline \multirow[t]{2}{*}{ Study } & \multicolumn{9}{|c|}{ Criteria $^{a}$} & \multirow[t]{2}{*}{ Total /9 } & \multirow[t]{2}{*}{ Quality } \\
\hline & 1 & 2 & 3 & 4 & 5 & 6 & 7 & 8 & 9 & & \\
\hline Lee SM et al. 2014 [70] & + & + & + & + & + & - & + & - & + & 7 & Moderate \\
\hline Mac Kinley E 2009 [71] & + & + & + & + & + & - & + & + & + & 8 & Moderate \\
\hline MacRae H 2011 [72] & + & + & + & + & + & + & + & + & + & 9 & High \\
\hline Mazaheri M et al. 2013 [73] & + & + & + & + & + & + & + & + & + & 9 & High \\
\hline Merrick R et al. 2016 [74] & + & + & + & + & + & - & - & + & + & 7 & Moderate \\
\hline Mjørud M et al. 2017 [75] & + & + & + & + & + & - & + & + & + & 8 & Moderate \\
\hline Molyneaux VJ et al. 2011 [76] & + & + & + & + & + & + & + & + & + & 9 & High \\
\hline Mushi D et al. 2014 [77] & + & + & - & + & + & - & + & + & + & 7 & Moderate \\
\hline Nowell ZC et al. 2013 [78] & + & + & + & + & + & + & + & + & + & 9 & High \\
\hline Nygård L 2008 [79] & + & + & + & + & + & - & - & + & + & 7 & Moderate \\
\hline Pesonen HM et al. 2013 [80] & + & + & + & + & + & - & + & + & + & 8 & Moderate \\
\hline Phinney A 2011 [81] & + & + & + & + & + & - & + & + & + & 8 & Moderate \\
\hline Pipon-Young FE et al. 2012 [82] & + & + & + & + & + & - & + & + & + & 8 & Moderate \\
\hline Read ST et al. 2017 [83] & + & + & + & + & + & - & + & + & + & 8 & Moderate \\
\hline Roach P et al. 2016 [84] & + & + & + & + & + & - & + & + & + & 8 & Moderate \\
\hline Rostad D et al. 2013 [85] & + & + & + & + & + & - & + & + & + & 8 & Moderate \\
\hline Sandberg L et al. 2017 [86] & + & + & + & + & + & - & + & + & + & 8 & Moderate \\
\hline Sharp BK 2017 [19] & + & + & + & + & + & - & + & - & + & 7 & Moderate \\
\hline Sixsmith A and Gibson G 2007 [87] & + & + & + & + & + & - & + & + & + & 8 & Moderate \\
\hline Stephan A et al. 2018 [88] & + & + & + & + & + & - & + & + & + & 8 & Moderate \\
\hline Svanström R et al. 2015 [89] & + & + & + & + & + & - & + & + & + & 8 & Moderate \\
\hline Tak SH et al. 2015 [90] & + & + & + & + & + & - & + & + & + & 8 & Moderate \\
\hline Tolhurst E and Weicht B 2017 [91] & + & + & + & + & + & + & + & + & + & 9 & High \\
\hline Thein et al. 2011 [92] & + & + & + & + & + & - & + & - & + & 7 & Moderate \\
\hline van Vliet D et al. 2017 [20] & + & + & + & + & + & - & + & + & + & 8 & Moderate \\
\hline Van Zadelhoff E et al. 2011 [93] & + & + & + & + & + & - & + & + & + & 8 & Moderate \\
\hline Vernooij-Dassen M et al. 2006 [94] & + & + & + & + & + & - & - & + & + & 7 & Moderate \\
\hline Vikström S et al. 2008 [95] & + & + & + & + & + & - & - & + & + & 7 & Moderate \\
\hline Weaks D et al. 2015 [96] & + & + & + & + & + & + & + & + & + & 9 & High \\
\hline Wolverson EL et al. 2010 [97] & + & + & + & + & + & - & - & + & + & 7 & Moderate \\
\hline Öman A and Nygård L 2005 [98] & + & + & + & + & + & - & - & + & + & 7 & Moderate \\
\hline
\end{tabular}

${ }^{a}$ CASP criteria 1.Clear research statement, 2.Qualitative methodology, 3.Research question appropriate, 4.Recruitment strategy, 5.Data collection, 6.Relationship researcher - participants described adequately, 7.Ethical considerations, 8.Data analysis, 9.Clear statements of findings

impact on daily life and some express that life loses its purpose and that happiness is gone. The participants describe concerns for the future [82]. The progression of dementia, and thereby the future, is unpredictable.

\section{Coping with dementia}

The experience of challenges and stress forms the backdrop for the experience of coping and the coping strategies people with dementia use. It is interesting to note that only two of the 74 included studies explicitly aimed to explore coping $[18,47]$.
The material emphasized two essential resources of coping that goes across the entire material: humour and social and emotional support. Humour is a personal resource that can be used actively to handle the symptoms of dementia. By laughing instead of crying, humour can be used as a safeguard in overwhelming situations. An ability to see the funny side can reduce stress, distract negative mood and elicit positive emotions. Social and emotional support are external resources of coping and describes the backing and practical help received from others; family, friends and other relations. Social support is important for coping with rising demands in life with dementia (See Table 4). 
Table 3 Presentation of studies included

\begin{tabular}{|c|c|c|c|}
\hline Authors \& year & Aim & Participants ${ }^{a}$ & Method \\
\hline $\begin{array}{l}\text { Aldridge H, Fisher P \& } \\
\text { Laidlaw K, } 2017 \text { [27] }\end{array}$ & $\begin{array}{l}\text { To expand on this limited } \\
\text { understanding and gain a } \\
\text { deeper insight as to how } \\
\text { shame is experienced and } \\
\text { made sense of by people } \\
\text { with early-stage dementia } \\
\text { by exploring this topic } \\
\text { directly with the people }\end{array}$ & $\begin{array}{l}N=5 \text { persons diagnosed } \\
\text { with dementia. AD (3), } \\
\text { Vascular (1), Mixed/vascular (2) } \\
\text { Diagnosis of dementia 2-6 } \\
\text { months prior to interview. } \\
\text { Age: } 74-90 \text { years } \\
\text { Women: } 33 \% \\
\text { UK }\end{array}$ & $\begin{array}{l}\text { Semi-structured interview in own } \\
\text { home. Analysis of interviews was } \\
\text { based upon the IPA procedure } \\
\text { outlined by Smith) and Yardley. }\end{array}$ \\
\hline
\end{tabular}

Aminzadeh F, Dalziel WB, Molnar FJ \& Garcia LJ, 2009 [28]

Aminzadeh F, Dalziel WB, Molnar FJ \& Garcia L, 2010 [29]

Atta-Konadu E, Keller HH \& Daly K, 2011 [30]

Barrett C \& Crameri P, 2015 [31]

Beattie A, Gavin D-W, Gilliard J \& Means R, 2004 [32]

Borley G \& Hardy S, 2017 [33]

Bronner K, Perneczky $\mathrm{R}$ McCabe R, Kurz A \& Harmann J, 2016 [34]
To outline the experiences and needs of lesbian, gay, bisexual and trans Australians living with dementia - and their partners

To demonstrate how interviews can be conducted with younger people with dementia.

To explore the lived experience of becoming cared for and the impact his has on identity and sense of self of women with Alzheimer's disease.
$\mathrm{N}=9$ persons living with dementia, partners (21) and service providers. Age range 47-79 years Australia

$N=14$ participants who had received a diagnosis of dementia and were using services.

UK

$N=8$ women with mild-tomoderate $A D$, living in own home

Mean age: 78 years (range 74-83 years) Mean MMSE: 20 (range $15-26)$ scored within the last 6 months

Living with partner: $100 \%$ Requiring assistance with I-ADL: $100 \%$ UK

To identify medical and social topics which become relevant in the period following diagnosis of $A D$, for which a decision may eventually need to be made and which has implications for the life and wellbeing of the persons with $A D$

$\mathrm{N}=5$ persons with $A D$, relatives (6) and professionals (13). Germany
Individual in-depth interviews. Field notes as supplementary data. Analyses were guided by the work of Corbin \& Strauss.

Individual in-depth interviews. Field notes as supplementary data. Analyses were guided by the work of Corbin \& Strauss.

Participants were interviewed yearly over a three-year period (the last year only 5 husbands and wives were still involved). First couples interviewed in dyads, and then individual interviews were accomplished 1 week to 1 month later. Data were analyzed using the constant comparative method described by Corbin \& Strauss.

In-depth interviews mostly face to face (20). Data were analyzed using qualitative data analysis for applied policy research in line with Ritchie and Spencer.

Semi-structured, individual indepth interviews

Data were transcribed and subjected to comparative textual analysis guided by the principles of Strauss \& Corbin

Individual semi-structured interviews performed twice (within 4 weeks). The first interview enabled the women to talk about their life and experience related to their diagnosis of AD. The second interview allowed for further exploration and clarification with open-ended questions. Data were examined with interpretative phenomenological analysis in line with Smith, Flowers \& Larkin.
Semi-structured face-to-face interviews.

Data were analyzed using content analysis in accord with Mayring. 
Table 3 Presentation of studies included (Continued)

\begin{tabular}{|c|c|c|c|}
\hline Authors \& year & Aim & Participants $^{a}$ & Method \\
\hline $\begin{array}{l}\text { Brorsson A, Øhman A, Lundberg S. } \\
\text { \& Nygård L, } 2011 \text { [35] }\end{array}$ & $\begin{array}{l}\text { To illuminate experiences of } \\
\text { accessibility in public space } \\
\text { in people with AD, with } \\
\text { particular focus on placed, } \\
\text { situations and activities that } \\
\text { they found to be important } \\
\text { for daily life }\end{array}$ & $\begin{array}{l}N=7 \text { persons diagnosed } \\
\text { with early } A D \text {, living in } \\
\text { ordinary housing } \\
\text { Sweden }\end{array}$ & $\begin{array}{l}\text { Repeated in-depth interviews. All, } \\
\text { except for one informant, were } \\
\text { interviewed twice. } \\
\text { Data were analyzed using open } \\
\text { coding in accord with Corbin and } \\
\text { Strauss. }\end{array}$ \\
\hline Chaplin R \& Davidson I, 2016 [36] & $\begin{array}{l}\text { To focus specially on the } \\
\text { experiences of people } \\
\text { developing a dementia } \\
\text { while still in employment } \\
\text { in the UK }\end{array}$ & $\begin{array}{l}N=5 \text { persons with } A D \text { still } \\
\text { being employed. } \\
\text { MMSE: score range } 25-28 \\
\text { Age range: } 58-74 \text { years } \\
\text { Women: } 20 \% \\
\text { UK }\end{array}$ & $\begin{array}{l}\text { Individual semi-structured } \\
\text { interviews on a single occasion. } \\
\text { Data were analyzed using } \\
\text { interpretative phenomenological } \\
\text { analysis. }\end{array}$ \\
\hline $\begin{array}{l}\text { Clare L, Rowland J, Bruce E, } \\
\text { Surr C \& Downs M, } 2008 \text { [37] }\end{array}$ & $\begin{array}{l}\text { To explore the subjective } \\
\text { experience of living with } \\
\text { dementia in residential care } \\
\text { and to understand the } \\
\text { psychological impact of } \\
\text { being in this situation }\end{array}$ & $\begin{array}{l}N=81 \text { persons diagnosed } \\
\text { with dementia living in } \\
\text { residential care homes. } \\
\text { UK }\end{array}$ & $\begin{array}{l}\text { An existing dataset consisting of } \\
\text { individual unstructured conversations } \\
\text { with people with dementia from a } \\
\text { study of well-being in residential } \\
\text { care were used. } \\
\text { The number of conversations } \\
\text { recorded with each participant } \\
\text { ranged from } 1 \text { to } 8 \text {. The total dataset } \\
\text { consisted of } 304 \text { transcripts. } \\
\text { Interpretative phenomenological } \\
\text { analysis as guiding design. }\end{array}$ \\
\hline $\begin{array}{l}\text { Clemerson G, Walsh S \& } \\
\text { Isaac C, } 2014 \text { [38] }\end{array}$ & $\begin{array}{l}\text { To explore the individuals' } \\
\text { subjective experiences of } \\
\text { young-onset dementia }\end{array}$ & $\begin{array}{l}\mathrm{N}=8 \text { persons diagnosed } \\
\text { with AD living at home. } \\
\text { MMSE: score range } 17-21 \\
\text { Age range: } 35-60 \text { years } \\
\text { Women: } 12.5 \% \\
\text { Living with someone } \\
\text { (partner or others): } 75.0 \% \\
\text { UK }\end{array}$ & $\begin{array}{l}\text { Individual semi-structured interviews } \\
\text { were performed. } \\
\text { Data were analyzed using } \\
\text { interpretative phenomenological } \\
\text { analysis. }\end{array}$ \\
\hline
\end{tabular}

Dalby P, Sperlinger DJ \& Boddington S, 2012 [39]

Derksen E, Vernooij-Dassen M, Gillissen F \& Scheltens P, 2006 [40]

De Witt L, Ploeg J \&

Black M, 2009 [41]

De Witt L, Ploeg J \&

Black M, 2010 [42]
To understand the experience of spirituality in the context of living with dementia. In addition, a second aim was to understand the experience of dementia in the context of spiritual belief

To describe and appraise the experiences, beliefs, and fears regarding the diagnosis of dementia in both patients and carers

To understand the meaning of living alone for older people with dementia.

To understand the meaning of living alone from the perspective of older people with Alzheimer disease or a related dementia.
$N=6$ persons diagnosed with dementia living at home (75\%), in assisted living (12.5\%) or in nursing home (12.5\%).

Age range: from 70-ties to 90 -ties

Women: $83.3 \%$

Living with partner: $16.7 \%$ UK

$N=18$ persons diagnosed with dementia and their family carers.

Mean MMSE score: 22

(range 15-30)

Mean age: 71 years

Women: 20\%

Living with partner $85 \%$.

The Netherlands

$\mathrm{N}=8$ women diagnosed with mild to moderate $A D$ or related dementia living alone in the community Canada

$\mathrm{N}=8$ women diagnosed with mild to moderate $A D$ or related dementia living alone in the community. Canada
Individual semi-structured interviews with participants were performed. Data were analyzed using interpretative phenomenological analysis.

Individual semi-structured interview with patient and the carer were performed separately. Two interviews with participants; the first 2 weeks after the diagnostic disclosure and 10 weeks later. Data were analyzed using the constant comparative method in line with Corbin \& Strauss.

Repeated face-to-face, openended interviews. All, except for two informants, were interviewed twice.

Data were analyzed using three techniques data analysis in accord with van Manen.

Repeated face-to-face, open-ended interviews. All, except for two informants, were interviewed twice. Data were analyzed using three techniques data analysis in accord with van Manen. 
Table 3 Presentation of studies included (Continued)

\begin{tabular}{llll}
\hline Authors \& year & Aim & Participants $^{\text {a }}$ & Method \\
\hline Digby R, Moss C \& & To understand how older & $\mathrm{N}=8$ persons with dementia & In-depth semi-structured interviews \\
Bloomer MJ, 2011 [43] & $\begin{array}{l}\text { patients with mild to moderate } \\
\text { dementia experienced the }\end{array}$ & Australia & using the communication \\
& transfer from acute to subacute & & techniques recommended by \\
care and settling-in period. & & Young and Manthorp. \\
& & Data were analyzed using \\
content analysis in accord \\
with Hsieh and Shannon.
\end{tabular}

Digby R \& Bloomer MJ, 2012 [44]

Duggan S, Blackman T, Martyr A \& Van Schaik P, 2008 [45]

Fleming R, Kelly $F$ \& Stillfried G, 2015 [46]

Frazer SM, Oyebode JR \& Cleary A, 2011 [47]

Genoe MR, Dupuis SL, Keller HH, Martin LS, Cassolato C \& Edward HG, 2010 [48]

Genoe MR, Keller HH, Martin LS, Dupuis SL, Reimer H, Cassolato C \& Edward G, 2012 [49]

Genoe MR \& Dupuis SL, 2014 [50]
To elicit the perspectives of current inpatients with dementia, and their family carers, about the environment/design features that they believe are necessary for people with dementia, and their family carers.

To explore the use of outdoor environment and how dementia impacts on it.

To identify the environmental features that are desirable in buildings used to provide care for people with dementia nearing the end of their lives

To explore how women who live alone with dementia see themselves and how they cope in their everyday lives

To explore the experience and meaning of food and mealtimes for persons with dementia living in the community and their primary partners in care

To explore the meaning and experience of change surrounding mealtimes for persons with dementia living in the community and their primary partners in care

To explore how persons with dementia think about and describe leisure in the context of their lives
$N=7$ persons with dementia staying in a sub-acute facility and carers (4)

Australia

$N=22$ persons diagnosed with early to moderate $A D$ or vascular dementia living in their own home, and carers (11 spouses/partners, 2 daughters, 1 carer/housekeeper) UK

$N=2$ persons with young onset dementia, family carers (10) and health care personnel (5).

Australia

\section{$N=8$ persons diagnosed} with dementia $(A D=5)$ living in their own home. UK

$N=27$ persons diagnosed with dementia $(A D=25)$ living in their own home together with their primary family caregivers (19 spousal relationships, 8 adult-child relationships).

Majority were in early stage of dementia

Age range: $56-88$ years

Women: $59.3 \%$

Living with someone: 100\% Canada

$\mathrm{N}=27$ persons diagnosed with dementia $(A D=25)$ living in their own home together with their primary family caregivers (19 spousal relationships, 8 adult-child relationships).

Majority were in early stage of dementia

Age range: $56-88$ years

Women: $59.3 \%$

Canada

$N=4$ persons with early stage dementia living in their own home.

Age range: $70-82$ years Women: $50 \%$
In-depth semi-structured interviews

Semi-structured individual interviews. Data were analyzed using NVivo and further in line with grounded theory.

Mixed method. Three focus group interviews.

In addition, a survey with experts in environmental design of care facilities for older people (21)

Interview data were analyzed using management software NVivo 8.

Individual, semi-structured interviews were performed. Data were analyzed using interpretative phenomenological approach.

Dyad interviews were followed by individual interviews within 2 weeks were conducted.

Data were analyzed using grounded theory approach as described by Charmaz - the constant comparative method.

Dyad interviews were followed by individual interviews within 2 weeks were conducted. Data were analyzed using grounded theory approach as described by Charmaz - the constant comparative method.

Individual interviews with each participant were accomplished. Data were also collected through participant observation and photo voice. 
Table 3 Presentation of studies included (Continued)

\begin{tabular}{|c|c|c|}
\hline Authors \& year & Aim & Participants $^{\mathrm{a}}$ \\
\hline & & $\begin{array}{l}\text { Living with partner: } 50 \% \\
\text { (both men) } \\
\text { Canada }\end{array}$ \\
\hline $\begin{array}{l}\text { Gill L, White L \& } \\
\text { Cameron ID, } 2011 \text { [51] }\end{array}$ & $\begin{array}{l}\text { To understand how people } \\
\text { with dementia receiving } \\
\text { community care services in } \\
\text { their own homes, perceive } \\
\text { interaction in the context of } \\
\text { their service experience }\end{array}$ & $\begin{array}{l}\mathrm{N}=22 \text { persons diagnosed } \\
\text { with dementia receiving } \\
\text { community care services } \\
\text { in their own home. } \\
\text { Australia }\end{array}$ \\
\hline $\begin{array}{l}\text { Gilmour JA \& } \\
\text { Huntington A, } 2005 \text { [52] }\end{array}$ & $\begin{array}{l}\text { To explore the experiences } \\
\text { of living with memory loss }\end{array}$ & $\begin{array}{l}N=9 \text { persons diagnosed } \\
\text { with dementia living at home. } \\
\text { New Zealand }\end{array}$ \\
\hline
\end{tabular}

Goodman C, Amador S, Elmore N, Machen I \& Mathie E, 2013 [53]

Hain D, Touhy TA, Compton Sparks D \& Engstrom G, 2014 [54]

Harman G \& Clare L, 2006 [55]

Harris PB, 2011 [56]

Hedman R, Hansebo G, Ternestedt BM, Hellström I \& Norberg A, 2013 [5] Ternestedt BM, Hellström I \& Norberg A, $2016[58]$
To explore how people with dementia discuss their priorities and preferences for end-of-life care, and how this might inform subsequent discussions with family and practitioners

To explore the experience of living with dementia from multiple perspectives, namely, the individual, spouse, and dyad of the person and spouse

To explore the experience of living with dementia with focus on what makes activities meaningful for people with dementia

To study factors of importance for maintaining and retention of friendship in early stage dementia

To explore the use of Harré's social constructionist theory of selfhood to describe how people with mild and moderate $A D$ express their sense of self.

To describe how five people with mild and moderate $A D$ express their personal attributes and life histories

To investigate how life in Norwegian nursing homes may affect experiences of dignity among persons with dementia
Method

Data were analyzed using van

Manen's phenomenological reflection.

Individual semi-structured interviews were performed.

Data were analyzed using thematicand constant comparison analyses.

Individual, semi-structured interviews using open questions were used. To assist participants, questions were provided on beforehand and many participants wrote reminder notes prior to the interview.

Thematic analyses were undertaken.

$\mathrm{N}=18$ persons diagnosed with dementia living in residential care homes. UK

Individual, semi-structured interviews in the form of a 'guided-conversation' were conducted as a part of a longitudinal mixed method study. Thematic analyses were undertaken.

$\mathrm{N}=6$ persons diagnosed with $A D$ and their spousal caregiver (6).

Mean MMSE: 23.3 (20-25)

Mean age: 79.3 (71-85) years

Women: $16.7 \%$

Living with partner: 100\% USA

$N=17$ persons diagnosed with dementia living in residential care homes, in addition their family caregivers (8), and staff (15). UK

$\mathrm{N}=8$ persons diagnosed with dementia $(\mathrm{AD}=7)$ living in their home.

Early stage of dementia Mean age: 75 (59-85) years Women: 100\% USA

$N=12$ persons diagnosed with $A D$ living in their own home. Sweden

$N=5$ persons diagnosed with mild to moderate $A D$. Age range: $59-78$ years Women: 60\%

Living with partners: $80 \%$ Sweden

$\mathrm{N}=5$ persons diagnosed with dementia living in nursing home.

Norway
Individual, semi-structured interviews conducted from multiple perspectives; the individual, spouse, and dyad of the person and spouse. Analyses were performed using the Giorgi's descriptive phenomenological approach.

Focus group design with a constructed question guide with residents, staff and relatives of the residents were performed. Mind map notes. Data were analysed using grounded theory approach with contents analysis.

Individual in-depth interviews were performed.

Data were analysed using grounded theory approach in accord with Glaser and Strauss

Individual, semi-structured interviews were performed. Data were analysed using phenomenological approach in accord with Harré's theory of social constructionist.

10 support group sessions during an 8 months period. approach in accord with McAdams and Graneheim and Lundman.

Individual interviews and observations field notes were used.

Data were analysed using qualitative phenomenological and interpretative hermeneutical approach in accord with Kvale \& Brinkman.
Data were analyzed using an abductive 
Table 3 Presentation of studies included (Continued)

\begin{tabular}{|c|c|c|c|}
\hline Authors \& year & Aim & Participants $^{\mathrm{a}}$ & Method \\
\hline $\begin{array}{l}\text { Hellström I, Eriksson H \& } \\
\text { Sandberg J, } 2015 \text { [60] }\end{array}$ & $\begin{array}{l}\text { To describe how older women } \\
\text { with dementia express the } \\
\text { importance of their homes } \\
\text { and chores in everyday life }\end{array}$ & $\begin{array}{l}\mathrm{N}=7 \text { women diagnosed } \\
\text { with dementia. } \\
\text { Age: } 65-84 \text { years } \\
\text { Living with spouse: } 100 \% \\
\text { Sweden }\end{array}$ & $\begin{array}{l}\text { Supplementary secondary analysis } \\
\text { of a longitudinal study exploring } \\
\text { ways in which people with dementia } \\
\text { and their spouses ( } 20 \text { couples) } \\
\text { experienced dementia over time. } \\
\text { Several individual interviews (3-5) } \\
\text { were performed. } \\
\text { Data were analyzed in accord } \\
\text { with the method of qualitative } \\
\text { description according to Sandelowski. }\end{array}$ \\
\hline
\end{tabular}

Herron RV \& Rosenberg MW, 2017 [61]

Hillmann A, Jones IR, Quinn C, Nelis SM \& Clare L, 2018 [62]

Hulko W, 2009 [63]

Johannessen A \& Möller A, 2011 [64]

Johannessen A, Möller A, Haugen PK \& Biong S, 2014 [65]

Karlsson E, Sävenstedt S, Axelsson K \& Zingmark K, 2014 [66]

Keller HH, Martin LS, Dupuis S, Genoe R, Edward HG \& Cassolato C, 2010 [67]
To examine how people with dementia relate to and within their communities as well as their perceptions of community support service.

(1) To identify the kinds of representations of dementia present in the accounts of those who speak for people with dementia.

(2) To situate these stories within their wider social and cultural contexts, to ascertain the extent to which they reflect, contribute to or challenge existing representations of dementia.

(3) To utilise Burchardt's work (2016) to consider what the implications might be of their circulation and accumulation in a narrative economy of dementia.

To explore the experience of older people with dementia and in which way socio-culture plays a role in diverse dementia patients' daily living

To find out how people experience living with earlyonset dementia, and to assess the implications for practice and the development of further services

To investigate and interpret metaphorical expressions of the lived experiences of everyday life in people with young-onset dementia

To explore how people with $A D$ present their life story

To explore the mealtimes to provide opportunity for social activity and emotional connection
$N=46$ community-dwelling people with dementia and their partners; spouse (39), daughter (2), sister (1), son (1). Diagnosis of dementia: 3 years (average)

Age: $56-93$ years

Women: $43 \%$

Canada

$\mathrm{N}=5$ people living with dementia and their partners (4) AD (2), Vascular dementia (2), mixed (1). Age: $49-83$ years Women: $40 \%$ UK

$\mathrm{N}=8$ persons diagnosed with dementia $(A D=7)$ living in their home and their relatives (50). Canada

$\mathrm{N}=20$ young persons with a diagnosis of dementia. Norway

$N=20$ young persons with a diagnosis of dementia. Age: $54-67$ years

Women: 40\%

Living with spouse: $75 \%$ Norway

$\mathrm{N}=9$ participants diagnosed with $A D$, living in their homes. MMSE: $19-25$

Age: $60-81$ years

Women: $55.5 \%$

Living with spouse: $88.9 \%$ (8) Sweden

$N=27$ participants with early to mild stage of dementia living in their home and their next of kin (28).
Qualitative case-study approach. Semi-structured interviews. All but two participants had a partner in care present with them. NVivo-coding according to Charmaz

The participants were interviewed twice, a few months apart. Analyzed with constant comparative method in line with Glaser \& Strauss and Silverman

Series of individual in-home interviews over 1-2 month and observation sessions were used. Data were analyzed in accord with grounded theory.

Individual, thematic interviews were conducted.

Data were analysed in line with grounded theory according to Glaser and Strauss,

Individual, thematic interviews were conducted.

Secondary analysis of the data in line with cognitivesemantic theory according to Lakoff \& Johnson.

Individual, narrative interviews were conducted.

Data were analyzed with the method for analysis of narrative in accord with Polkinghorne.

Active interviews with both individual and dyads were performed.

Data were analyzed using 
Table 3 Presentation of studies included (Continued)

\begin{tabular}{ll}
\hline Authors \& year & Aim \\
\hline & \\
& \\
Langdon SA, Eagle A \& Warner J, & $\begin{array}{l}\text { To explore the social effects } \\
\text { of diagnosis of dementia }\end{array}$
\end{tabular}

Lawrence RM, Samsi K, Banerjee S, Morgan C \& Murray J, 2011 [69]

Lee SM, Roen K \&Thornton A, 2014 [70]

Mac Kinlay E, 2009 [71]

MacRae H, 2011 [72]

Mazaheri M, Eriksson LE, Heikkilä K, NasraBadi AN, Ekman SL \& Sunvisson H, 2013 [73]

Merrick K, Camic PM \& O'Shaughnessy M, 2016 [74]

Mjørud M, Engedal K, Røsvik J \& Kirkevold M, 2017 [75]
The subjective reality of living with dementia from the perspective of three minority ethnic groups.

Thoughts and other reactions to the diagnosis dementia

To explore personal experiences of receiving a diagnosis and to investigate aspects of the experience of adjusting and adapting to dementia

To examine spirituality and meaning in the experience of dementia of older Latvians who had immigrated to Australia during the war II

To examine how others' reactions to and treatment of persons living with early stage AD influence their experience of dementia

To describe experience of living with dementia in Iran

To enrich understanding of the experience of dementia from a relational perspective

To investigate the personal experience of living in a nursing home over time and what makes life better or worse from the perspective of the person with dementia

$\begin{array}{ll}\text { Participants }^{\text {a }} & \text { Method } \\ \text { Canada } & \text { grounded theory methodology } \\ & \begin{array}{l}\text { in accord with Charmaz and } \\ \text { team analysis. }\end{array}\end{array}$

$\mathrm{N}=12$ persons diagnosed with dementia living in their own home.

MMSE range: 19-30 Women: $50 \%$

UK

$N=30$ persons diagnosed with dementia living at home or in sheltered accommodations (4). UK

$N=10$ persons diagnosed with mild $A D$, living at home. Mean MMSE: 25 (22-30) Mean age: 69 (57-84) years Women: $70 \%$ Living with partner: $50 \%$ UK

$\mathrm{N}=3$ persons diagnosed with dementia living in an aged-care facility. MMSE: 18-20

Age: 87-94 years Australia

$\mathrm{N}=9$ persons diagnosed with early stage $A D$. living at home (7), in senior's residence (1) or in a convent (1).

Mean age: 74 years

Women: $22.2 \%$

Living with partner: $44.4 \%$ Canada

$N=15$ persons diagnosed with moderate $A D$, or Vascular dementia, living at home.

Mean MMSE: 16.5

(range: 14-19)

Mean age: 72 (range 60-87)

years

Women: 40\%

Living with someone: $80 \%$ Iran

$\mathrm{N}=7$ persons with dementia and their care partners (7). AD (4), frontotemporal dementia (1), vascular dementia (1) mixed (1). Age range: $65-87$ years Women: $29 \%$

UK

$\mathrm{N}=12$ persons with dementia living in nursing home care units for persons with dementia Norway
Individual semi-structured in-depth interviews were performed. Data were analyzed in accord with interpretative phenomenological approach.

Individual in-depth interviews were performed.

Data were analyzed using grounded theory approach in accord with Glaser.

Individual, semi-structured interviews were performed. Data were analyzed using interpretative phenomenological approach.

Individual in-depth interviews were performed.

Data were analyzed using grounded theory in accord with Strauss and Corbin.

Individual in-depth, interviews using a symbolic interactionist perspective were performed. Data were analysed using inductive emergent process in accord with Coffey \& and Taylor \& Bogdan.

Individual semi-structured interviews were performed. Data were analysed using content analysis in accord with Graneheim and Lundman.

Semi-structured dyad interviews. Data were analyzed using an interpretative phenomenological approach.

Repeated individual, unstructured interviews 3 months apart. Field observations.

Data were analyzed using phenomenological-hermeneutical analysis in accordance with Lindseth and Norberg. Atkinson, Lofland \& Lofland, 
Table 3 Presentation of studies included (Continued)

\begin{tabular}{lll}
\hline Authors \& year & Aim & Participants $^{\text {a }}$ \\
\hline Molyneaux VJ, Butchard S, & To understand 'couple-hood' as & N=5 persons diagnosed \\
Simpson J \& Murray Cl, 2011 [76] & it is co-constructed by the couple & with AD. and their partner \\
& when one partner has dementia. & living at home. \\
& & UK
\end{tabular}

Mushi D, Rongai A, Paddick SM, Dotchin C, Mtuya C \& Walker R, 2014 [77]

Nowell ZC, Thornton A \& Simpson J, 2013 [78]

Nygård L, 2008 [79]

Pesonen HM, Remes AM \& Isola A, 2013 [80]

Phinney A, 2011 [81]

Pipon-Young FE, Lee KM, Jones F \& Guss R, 2012 [82]

Read ST, Toye C \&

Wynaden D, 2017 [83]
To explore the socio-cultural beliefs surrounding dementia and the life experience of people with dementia and their caregivers in the Tanzania

To understand personhood by exploring the subjective experiences of those with dementia in UK

To explore how people with dementia who live alone experienced the meaning of their everyday technology, such as telephone and electronic equipment, and the use of it.

To explore the shared experience of dementia from the viewpoint of people with newly diagnosed dementia and their family members, and to understand how they manage their lives after the diagnosis

To understand how people with dementia understand their lives as making sense and worth living.

To explore the experiences of younger persons with dementia and develop an understanding of helpful support

To identify areas of the service in need for change
$N=41$ persons diagnosed with dementia living at home and their caregivers, but only 25 persons with dementia were interviewed. Tanzania

$\mathrm{N}=7$ people diagnosed with dementia living in dementia care units. UK

$\mathrm{N}=8$ persons diagnosed with dementia living at home.

Sweden

$\mathrm{N}=8$ persons diagnosed with dementia ( $A D=6$ ) living in their home or nursing home/assisted living facility (4) and their family members (8). Finland

$\mathrm{N}=9$ persons with mild to moderate $A D$, living in own home. Canada

$\mathrm{N}=8$ persons diagnosed with dementia living in their home. UK

$N=24$ persons diagnosed with dementia, living in own home. AD (8), Vascular dementia (3), Frontal Lobe dementias (3), Semanticdementia (1) and Posterior cortical atrophy (1). Eight partici-pants did not know the type of dementia) Women: $50 \%$

Living with someone: $70 \%$

Method

The couples were interviewed

simultaneously.

Data were analyzed using

constructivist grounded theory approach in accord with Charmaz.

Semi structured paired interviews

(25) and individual interviews

(16) with the caregiver alone were performed.

Data were analyzed using content analysis.

Individual semi-structured i ndividual interviews were performed.

Data were analyzed using an interpretative phenomenological approach.

Repeated individual interviews and observations (for 3 weeks) were performed. Two to four sessions of interviews and observations pr. person, each session lasting between 1 to $2 \mathrm{~h}$. Data were analyzed using a phenomenological, hermeneutical approach.

Conversational, low structured face-to-face interviews. Unstructured observations were conducted during the interviews; field notes were written after each interview. Descriptive analysis using grounded-theory framework and constant comparative analysis in accord with Corbin \& Strauss.

Repeated in-depth conversational interviews. Participant observation.

Action research across three phases; semi-structured individual interviews and field notes were used. Data were analyzed using action research; interpretative approach including thematic analysis techniques in line with Charmaz and concept mapping in accord with McNiff \& Whitehead.

Individual semi-structured interviews. Field notes and memos were also collected to add contextual meaning to data collected from participants. Questions focused on participants' experiences of the onset of their dementia, the impact of the diagnosis on themselves and their family, 
Table 3 Presentation of studies included (Continued)

\begin{tabular}{|c|c|c|c|}
\hline Authors \& year & Aim & Participants $^{a}$ & Method \\
\hline & & Australia & $\begin{array}{l}\text { plus their future expectations } \\
\text { of living with dementia. } \\
\text { This research used an application } \\
\text { of the Grounded Theory (GT) } \\
\text { method developed by } \\
\text { Glaser and Strauss (2012). }\end{array}$ \\
\hline $\begin{array}{l}\text { Roach P, Drummond N \& } \\
\text { Keady J, } 2016 \text { [84] }\end{array}$ & $\begin{array}{l}\text { To develop deeper understanding } \\
\text { of the family experience of } \\
\text { transition in early-onset dementia } \\
\text { and to develop a representative } \\
\text { model of this experience }\end{array}$ & $\begin{array}{l}N=9 \text { persons with early } \\
\text { onset dementia and their } \\
\text { family members ( } 11) \\
\text { AD ( } 7) \text {, mixed ( } 1 \text {, posterior } \\
\text { cortical atrophy ( } 1 \text { ) } \\
\text { Age range: } 58-68 \text { years }\end{array}$ & $\begin{array}{l}\text { Individual, initial and follow-up } \\
\text { semi-structured interviews. } \\
\text { Data were analyzed in accord } \\
\text { with a framework approach to } \\
\text { qualitative data analysis by Ritchie } \\
\text { and Spencer. }\end{array}$ \\
\hline
\end{tabular}

Rostad D, Hellzen O \& Enmarker I, 2013 [85]

Sandberg L, Rosenberg L, Sandman P-O \& Borell L, 2017 [86]

Sharp BK, 2017 [19]

Sixsmith A \& Gibson G, 2007 [87]

Stephan A, Bieber A, Hopper L, Joyce R, Irving K. Zanetti $\mathrm{O}$, Portolani E, Kerpershoek L, Verhey F, de Vugt M, Wolfs $C$, Eriksen S, Røsvik S, Marques MJ, Gonçalves-Pereira M, Sjölund BM, Jelley H, Woods B \& Meyer G, 2018 [88]
To gain understanding of the lived experience of younger persons with dementia ( $<65$ years) who lived at home and suffered with early onset and the meaning that could be found in their experiences.

To explore and better understand how people with dementia, living at home,

experience risks in their daily life and how they handle these situations.

To describes how people with dementia perceive their experiences of stress, and how people with dementia cope with the stress they experience?

To study: the role and importance of music in the lives and activities of the participants, the benefits they derived from music and music-related activities

Explore the perspectives of people with dementia, their informal carers and health and social care professionals of accessing and using formal care and services. Aiming to improve the understanding of the facilitators and barriers to the access to and the use of formal dementia care for the further development of appropriate services and interventions.
$\mathrm{N}=12$ persons with mildto-moderate dementia, living in wn home AD (9), Vascular dementia (2), Levy Body (1) Mean age: 77 years (range 67-87) Women 50\%

Living with someone: $66.6 \%$ Sweden

$N=21$ persons with dementia living in own home

AD (13), Vascular dementia (7),Mixed (1)

Mean age: 65.9

Women: $52.3 \%$

Living with someone:66.7\% UK

$N=26$ persons diagnosed with dementia living in their home (16) or staying in care homes (10) and their family caregivers. Age: 62-96 years Women: 69.2\%

Living with someone: $70 \%$ UK

$N=51$ persons with dementia, 96 informal carers and 114 professionals All types of dementia included.

Mean age: 76 (range 54-96)

Living in own home: $92.2 \%$

Women: 54.9\%

Living with someone:60.8\% Germany, Italy, Portugal, Sweden, Norway, UK, Ireland, the Netherlands
Individual, narrative individual interviews in a conversational style with broad open-ended questions were used. Phenomenological hermeneutic approach to the analysis in line with Lindseth and Nordberg.

Semi-structured individual interviews with open-ended questions

The interviews were analysed in steps using a qualitative content analysis approach in line with Granheim \& Lundman.

Focus groups.

The study is an interpretative phenomenological analysis (IPA) in accordance with Smith, Flowers, \& Larkin. NVivo Qualitative Data Analysis program was used.

Individual interviews in their natural setting, at home (16-18) and in the care homes (8-10) were performed. Open ended interviews, which were loosely structured.

Observational data from private home settings were gathered.

Focus groups.

Qualitative content analysis using open coding was performed in each county, according to Elo \& Kyngas $\mathrm{H}$ and Graneheim \& Lundman. To ensure consistency and methodological rigor, a manual was provided to all the partners. The analysis was supported by the software MAXQD Aplus version 11 (VERBI GmbH, Berlin, Germany). 
Table 3 Presentation of studies included (Continued)

\begin{tabular}{|c|c|c|c|}
\hline Authors \& year & Aim & Participants $^{\mathrm{a}}$ & Method \\
\hline Svanström R \& Sundler AJ, 2015 [89] & $\begin{array}{l}\text { To elucidate the phenomenon } \\
\text { of living alone with dementia } \\
\text { and having a manifest care need }\end{array}$ & $\begin{array}{l}\mathrm{N}=6 \text { persons with } \\
\text { dementia lining in own } \\
\text { homes. } \\
\text { Sweden }\end{array}$ & $\begin{array}{l}\text { Several conversational } \\
\text { interviews and field notes. } \\
32 \text { visits with six participants. } \\
\text { Data were analyzed in } \\
\text { accord with an in-depth } \\
\text { phenomenological analysis. }\end{array}$ \\
\hline $\begin{array}{l}\text { Tak SH, Kedia S, Tongumpun TM \& } \\
\text { Hong SE, } 2015 \text { [90] }\end{array}$ & $\begin{array}{l}\text { To describe types of current } \\
\text { activity involvement and barriers } \\
\text { to activities reported by nursing } \\
\text { home residents with dementia }\end{array}$ & $\begin{array}{l}N=37 \text { nursing home } \\
\text { residents with dementia. } \\
\text { USA }\end{array}$ & $\begin{array}{l}\text { Individual short, open-ended } \\
\text { interviews (31) and individual } \\
\text { in-depth interviews (6) were } \\
\text { performed. } \\
\text { Data were analyzed in accord } \\
\text { with descriptive, content analysis } \\
\text { within ethnographic framework. }\end{array}$ \\
\hline Tolhurst E \& Weicht B, 2017 [91] & $\begin{array}{l}\text { Explore how men with } \\
\text { dementia seek to preserve } \\
\text { their own personhood in } \\
\text { response to the impacts of the } \\
\text { condition. Explore how men }\end{array}$ & $\begin{array}{l}\mathrm{N}=14 \text { men with dementia } \\
\text { and their spouse, living at } \\
\text { home } \\
\text { Mild to moderate AD (12), } \\
\text { Mild Levy Body (1), Moderate }\end{array}$ & $\begin{array}{l}\text { Two semi-structured dyad } \\
\text { interviews of all } 14 \text { couples, with } \\
6 \text { months between each interview. } \\
\text { Narrative analysis according to } \\
\text { Riessman, } 2008\end{array}$ \\
\hline
\end{tabular}

with dementia seek to preserve their own personhood in response to the impacts of the condition. The authors claim that there is a lack of a masculine-gendered portrayal of the experience of dementia.

Thein NW, D' Souza G \&

Sheehan B, 2011 [92]

To explore the subjective experience of people with dementia of the move to a care home.

van Vliet D, Persoon A, Bielderman A, Explore how people with YOD Bakker C, Koopmans RTCM \& Gerritsen DL, 2017 [20] shape their daily lives to retain a sense of usefulness.

Van Zadelhoff E, Verbeek $\mathrm{H}$, Widdershoven $\mathrm{G}$, van Rossum E \& Abma T, 2011 [93]

Vernooij-Dassen M, Derksen E, Scheltens P \& Moniz-Cook E, 2006 [94]

Vikström S, Josephson S, Stigsdotter-Neely A \& Nygård L, 2008 [95]
Vascular dementia (1)

Mean age: 73.5 (range 58-89) UK

$\mathrm{N}=18$ persons with mild to moderate dementia moving in to nursing home UK

$N=18$ persons with dementia living in own home, and 21 informal care givers AD (8), Fronto temporal (3) Vascular dementia (1), Mixed (1) Not specified $(n=5)$ Mean age: 63.5 (range 57-70) Women: $38.9 \%$

Living with someone: $75 \%$

The Netherlands

$\mathrm{N}=5$ persons diagnosed with dementia living in a non-profit nursing home, in addition, residents' family members (4) and staff (5). The Netherlands

$\mathrm{N}=18$ persons with dementia living in their own home and their family carers.

Mean MMSE: 22 (range 15-30) Mean age 71 years

Women: $22.2 \%$

Living with someone: $83.3 \%$

The Netherlands

$N=26$ persons with dementia living in their home and their caregiving spouses (26).

Sweden
Repeated semi-structured individua interviews before and after moving to nursing home.

Systematically coding with NVivo using the headings for the interview as major codes.

Focus groups, using a discussion guide with open-ended questions. Qualitative content analysis in line with Graneheim \& Lundman and Elo \& Kyngas.

The analysis was supported by the softwear Atlas.ti.

Individual in-depth interviews with open-ended questions were performed separately with each of the participants. Observations and field notes were taken. Inductive and theoretical analysis was used.

Individual semi structured interviews about 2 weeks and 12 weeks after diagnosis were performed of PWD and family caregivers.

Constant comparative analysis using grounded theory in accord with Corbin \& Strauss.

Individual semi-structured individual interviews with open-ended questions were performed for PWD and caring spouse.

Analyzed using constant comparative method in line with grounded theory by Corbin \& Strauss. 
Table 3 Presentation of studies included (Continued)

\begin{tabular}{|c|c|c|c|}
\hline Authors \& year & Aim & Participants $^{\mathrm{a}}$ & Method \\
\hline $\begin{array}{l}\text { Weaks D, Wilkinson H } \\
\text { \& McLeod J, } 2015 \text { [96] }\end{array}$ & $\begin{array}{l}\text { To explore the ways in which } \\
\text { people with dementia, and those } \\
\text { close to them, negotiated the task } \\
\text { of disclosure of the diagnosis }\end{array}$ & $\begin{array}{l}\mathrm{N}=5 \text { persons with early } \mathrm{AD} \\
\text { living in their home, and } \\
\text { persons close to them (18). } \\
\text { Age: } 68-79 \text { years } \\
\text { Women: } 60 \% \\
\text { Living with partner: } 80 \% \\
\text { UK }\end{array}$ & $\begin{array}{l}\text { Sequential interviews combined } \\
\text { with participant observation over a } \\
6 \text { months period. } \\
\text { Data were analyzed with Grounded } \\
\text { Theory approach in accord with } \\
\text { Corbin and Strauss. NVivo Qualitative } \\
\text { Data Analysis program was used. }\end{array}$ \\
\hline $\begin{array}{l}\text { Wolverson EL, Clarke C } \\
\text { \& Moniz-Cook E, } 2010 \text { [97] }\end{array}$ & $\begin{array}{l}\text { To investigate the subjective } \\
\text { experience of hope of people } \\
\text { with dementia }\end{array}$ & $\begin{array}{l}\mathrm{N}=10 \text { persons diagnosed } \\
\text { with } A D \text { living in their home. } \\
\text { UK }\end{array}$ & $\begin{array}{l}\text { Individual semi-structured } \\
\text { interviews with open-ended } \\
\text { questions were performed. } \\
\text { Data were analyzed using } \\
\text { interpretative phenomenological } \\
\text { approach in line with Smith. }\end{array}$ \\
\hline Öhman A \& Nygård L, 2005 [98] & $\begin{array}{l}\text { To uncover and describe the } \\
\text { meaning and motives for } \\
\text { engagement in self-chosen } \\
\text { daily life occupation for elderly } \\
\text { individuals with AD dwelling in } \\
\text { community. }\end{array}$ & $\begin{array}{l}\mathrm{N}=6 \text { community-dwelling } \\
\text { persons diagnosed with } \mathrm{AD} \text {. } \\
\text { Sweden }\end{array}$ & $\begin{array}{l}\text { Repeated individual interviews and } \\
\text { observations. Totally two or three } \\
\text { times per person. } \\
\text { A qualitative comparative analysis } \\
\text { method was used in accord with } \\
\text { Bogdan \& Biklen. }\end{array}$ \\
\hline
\end{tabular}

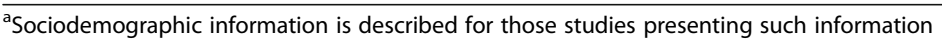

The analysis revealed four overall categories of coping strategies: (1) Keep going and holding on to life as usual; (2) Adapting and adjusting to the demands from the situation; (3) Accepting the situation; and (4) Avoiding the situation (See Table 5):

\section{Keep going and holding on to life as usual}

This category relates to people with dementia continuing doing the same things they used to, taking 1 day at a time. They try to live their lives in the same way and hold on to the same activities as before they became ill. The underlying reason for this may be that they wish to do as much as they can before the progression of dementia reduces their abilities.
The focus is on the present and to holding on to established routines and social relations. The category consists of the following subcategories: (a) Preserving identity; (b) Normalising the situation; and (c) Contributing to society.

Preserving identity refers to holding on to the identity that defines them as a person. They put effort into maintaining social roles and relations. They remind themselves and others of past achievements to preserve identity and self-esteem. By holding on to remaining aspects of themselves, they continue to live with the same sense of self as they have had for years.

Normalising the situation describes how people with dementia attempt to carry on with life and how they try to

Table 4 Results coping resources: Examples of condensed meaning units

\begin{tabular}{|c|c|c|}
\hline Category & $\begin{array}{l}\text { Humour } \\
{[27,40,47,49,50,63,68,73,74]}\end{array}$ & $\begin{array}{l}\text { Social and emotional support } \\
{[30,34,40,49,51,57,66,67,72,81,94,95]}\end{array}$ \\
\hline Condensed meaning unit & $\begin{array}{l}\text { Humour to cope with psychic pain [47]. } \\
\text { Taking control of dementia by minimising its impact } \\
\text { and using humour when describing coping strategies [47]. } \\
\text { Using humour to cope with the painful awareness of } \\
\text { memory decline [47]. } \\
\text { Humour and spirituality to cope [49]. } \\
\text { Using humour and laughing at one selves helped handle } \\
\text { the change and challenge [50]. } \\
\text { Using humour to help dealing with dementia [68]. } \\
\text { Using humour as strategy [73]. } \\
\text { Dismissing the significance of memory loss, and use } \\
\text { humour to cope [63]. } \\
\text { Using humour as a saviour [74]. } \\
\text { Laughter and humour [27]. }\end{array}$ & $\begin{array}{l}\text { Taking part in activities leading to connection with } \\
\text { others [66] } \\
\text { Mobilizing resources by accessing external services and } \\
\text { friends and families [49] } \\
\text { Acknowledging the value of receiving support [51]. } \\
\text { Holding on to their roles in valuable relationships [40]. } \\
\text { Promoting reciprocity and maintenance of relationship } \\
\text { through food role changes [30]. } \\
\text { Sharing emotions [40]. } \\
\text { Letting the family steer, represents a shifting orientation } \\
\text { toward what is good and meaningful in life [81] } \\
\text { Feeling lucky to be supported by family and home care [57]. } \\
\text { Expects their relatives to take care of them. Postponing } \\
\text { the decisions about the future [34]. } \\
\text { Becoming stupid if you don't talk to people [67] } \\
\text { Fortunate to be married and being looked after [30]. } \\
\text { Holding on to roles in social relationships [94]. } \\
\text { Continuing to interact regularly with friends [72]. } \\
\text { Sharing the diagnosis with their children [40]. } \\
\text { Seeking information about dementia and support [40]. } \\
\text { Nearness to the caregiver as an asset [95] }\end{array}$ \\
\hline
\end{tabular}




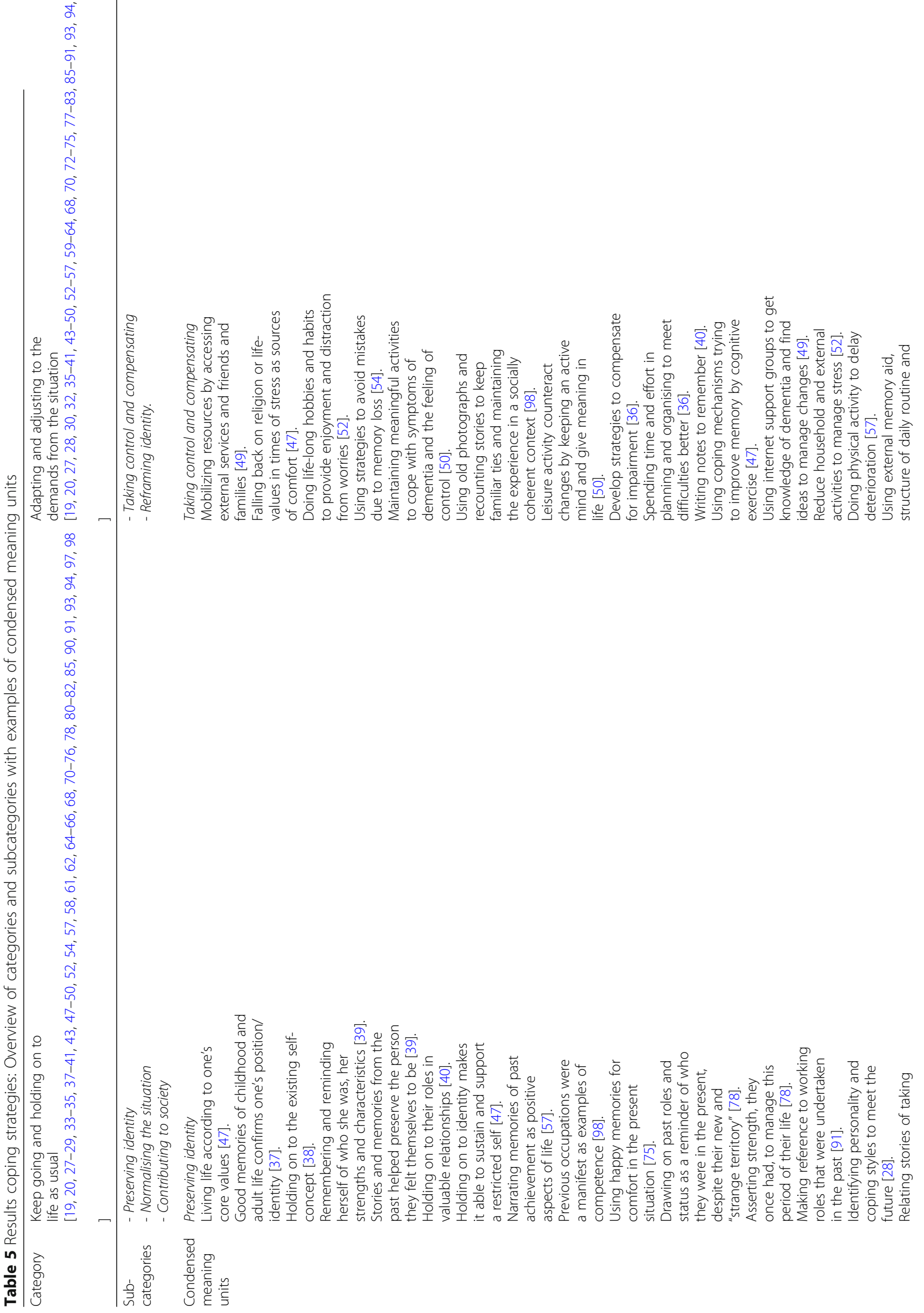




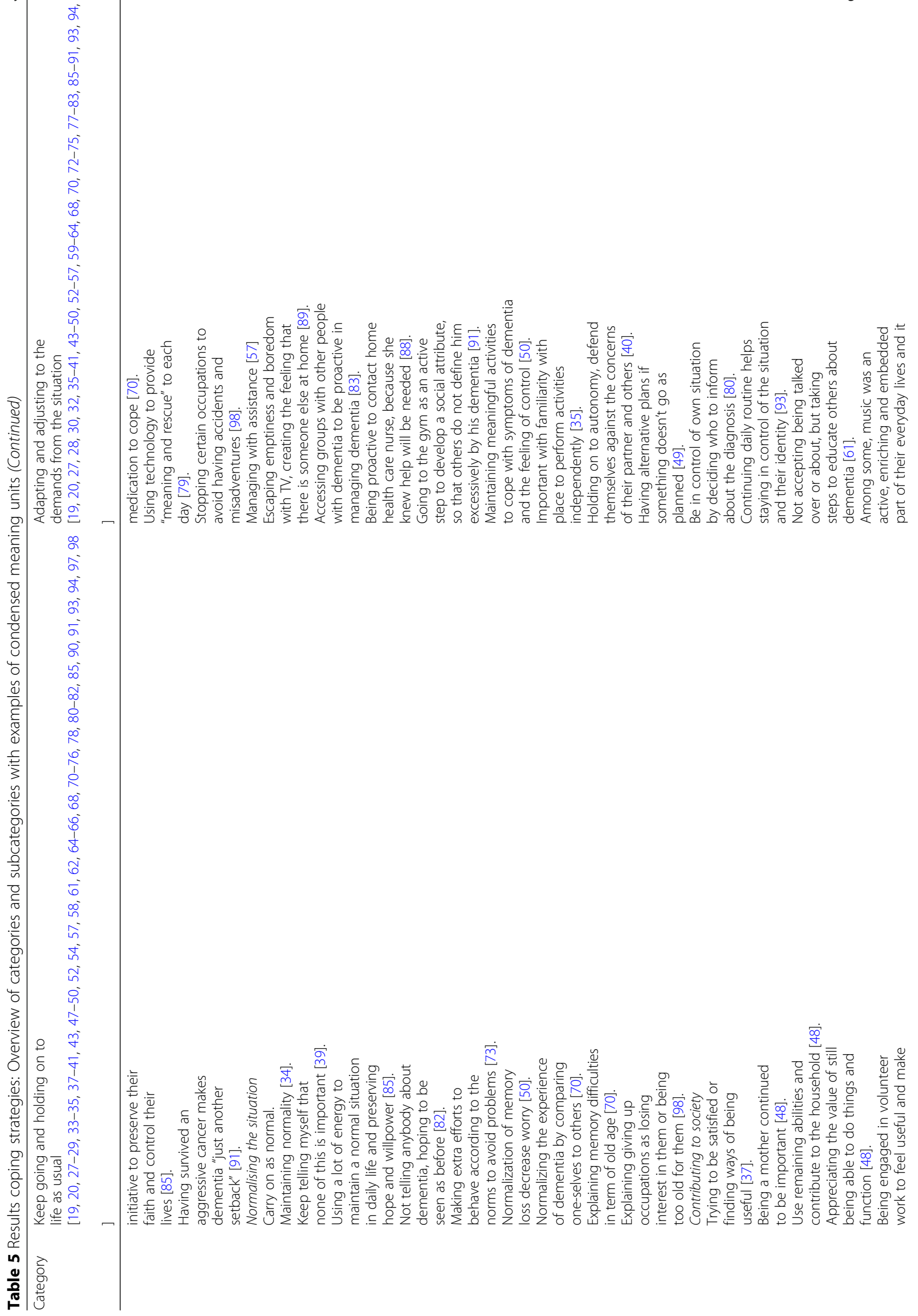




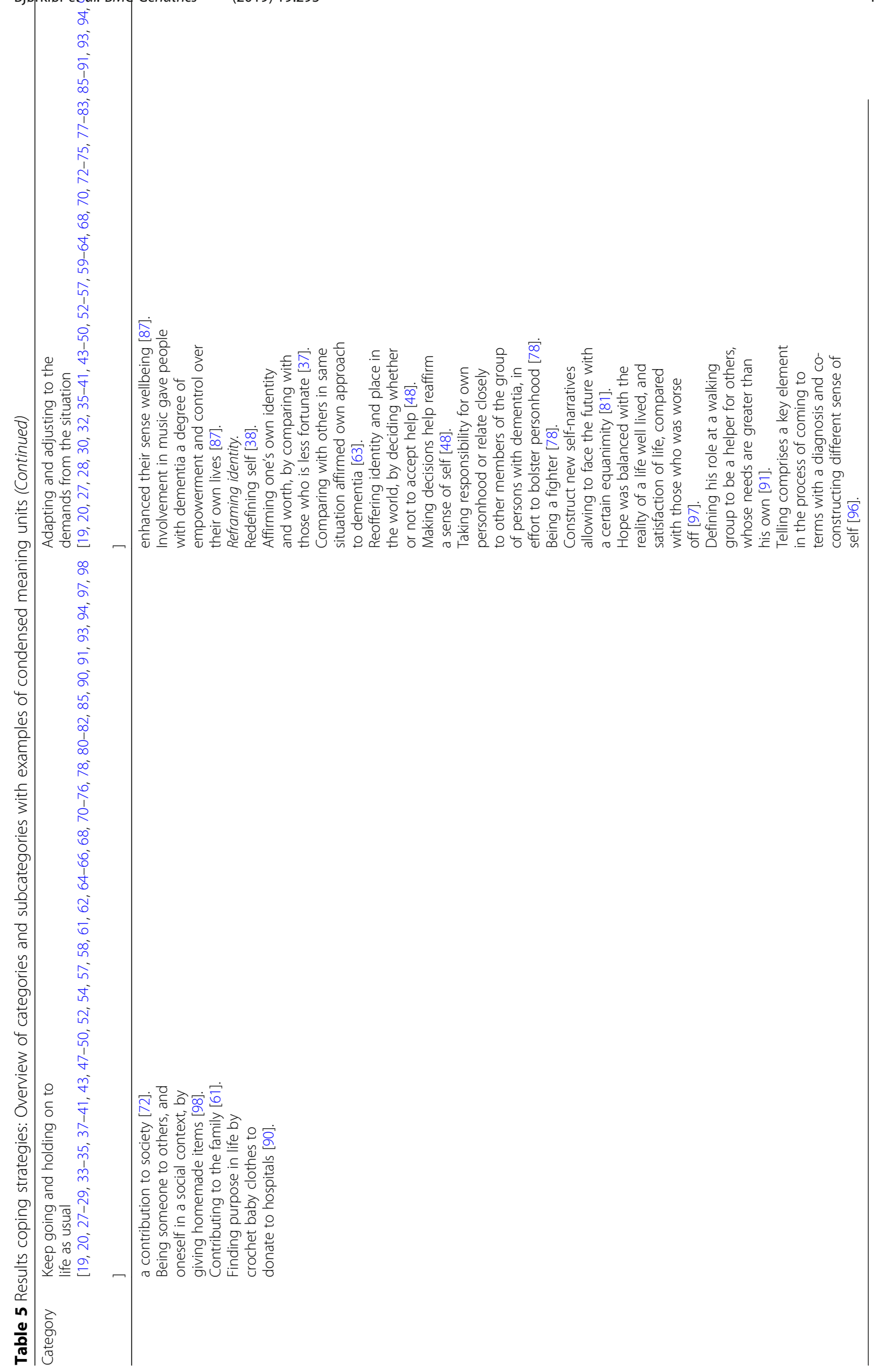


maintain a normal situation in daily life. It also refers to the effort they make to convince themselves and others that difficulties of memory loss or other challenges following dementia can be understood and explained as normal. They often compare themselves with others who forget things in order to normalise their own symptoms. By using this strategy, they seek to reduce their own worry and avoid negative response from surrounding people.

Contributing to society refers to the value of still being able to do meaningful activities and being useful. Many express a need or wish to use their remaining abilities and resources to help family or others for example by volunteer work.

\section{Adapting and adjusting to the demands from the situation}

This category of coping describes how people adapt and adjust by changing their own expectations towards themselves and activities they can perform. They seek information about dementia to be able to plan and prepare for the future. It also involves being active and doing changes in order to handle the situation. The category consists of the subcategories: (a) Taking control and compensating; and (b) Reframing identity.

Taking control and compensating describes what the person does to continue being both physically and cognitively active. Additionally, in order to make life work despite their cognitive decline they find ways of doing things differently They emphasize that having regular routines, writing down important things and using technological aids are good tools to help them maintain function. The subcategory also relates to the willingness to ask for and accept practical help from others, decide who should know about the diagnosis, and stick to familiar routines and places.

Reframing identity refers to how the person build identity by thinking differently about themselves and comparing their lives to the lives of those who are worse off. They construct a new self-narrative as one more fortunate, which gives hope for the future and appreciation of life. Also, by being active in making decisions in life, they take responsibility for own personhood and autonomy.

\section{Accepting the situation}

This category includes acknowledgement of the situation and the diagnosis of dementia. It is an acceptance of memory loss and other symptoms of dementia and a recognition of what they can do for themselves and when assistance from others is needed. The person with dementia reconciles with life as it is, though it can be a resigned acceptance. This category consists of the subcategory position in life.

Position in life is about acknowledging the dementia diagnosis and the consequences of the disease and focusing on strengths and possibilities. Dementia is described as a challenge or a problem, not "the end of the world".
Some have lived through challenging situations earlier in life, either it is related to health or e.g. having lived through a war. The positive orientation can be understood as a desire of living well, not letting dementia take over their life and having hopes for the future regardless the prospect.

\section{Avoiding the situation}

People with dementia may experience challenging situations in which they feel unskilled or inadequate due to the cognitive decline. In addition, having a diagnosis of dementia and experience the condition develop can be stressful and threatening to the experience of security and sense of self. Coping by trying to avoid stressful situations could concern an active resistance to adaption, change or to accepting help because this may imply accepting dementia and the progression of the symptoms. The person with dementia can use strategies that actively redirects focus or refrain from the exposed situations. For instance, by changing subject in a conversation or avoiding situations by using distractions such as being active, keeping occupied or compensate. The focus is less on handling a "threat" that emerges, but more on keeping a distance and avoiding it in advance. This can include not thinking and talking about the future, withdrawal and not taking initiative because this could mean being exposed as cognitively impaired.

\section{Balancing the struggle of living with dementia}

The four categories of strategies presented in the material do not necessarily follow each other in a linear process of coping ending in acceptance of the situation. Instead, they should be seen as potential strategies when meeting challenges and stress following dementia. The participants reported using several strategies at the same time and they employed different strategies depending on appraisals of the demands from the situation they encountered. Hence, the choice of strategies will be influenced by not only available resources of coping, but also the situation and context, and several strategies can be used for the same situation and challenge. The coping process and the four strategies described by people with dementia can be summed up in the overall theme balancing the struggle of living with dementia.

\section{Discussion}

The main findings from this study revealed two main resources of coping: (1) Humour; and (2) Practical and emotional support, and four overall strategies in which people with dementia cope with the challenges they experience: (1) Keep going and holding on to life as usual; (2) Adapting and adjusting to the demands from the situation; (3) Accepting the situation; and (4) Avoiding the situation. The coping process and the four strategies 
can be summarized in the theme; balancing the struggle of living with dementia.

The two studies in our data material explicitly exploring coping in people with dementia had different perspective. Frazer et al. [47] studied how women who live alone with dementia cope in their everyday lives. They found that their participants were actively engaged in re-constructing their sense of self, using a variety of coping strategies. Sharp [18] described how people with dementia cope with the stress they experienced. The author highlighted the topic of learning to do things differently and establishing coping strategies that provide control. Her participants described individual potential for adapting and coping with the stressful aspects of living with dementia. Even though the two papers do not present their interview guides, there are reasons to believe that the participants have been asked to describe their ways of coping.

However, most of the papers included in our study did not ask the participants explicitly about their coping strategies, all articles described different ways in which people with dementia cope with challenges in their daily lives. Coping strategies are responses to stress such as specific challenges and daily struggles. Our findings describe both problem- and emotion- focused coping strategies. A problem-focused strategy can be to do something yourself, but it can also mean letting others do something for you when the aim is to minimize the stressful situation. Emotion-focused strategies may relieve a person's situation by creating distance to the challenges, for instance by avoiding confrontations regarding symptoms and thereby shielding themselves from the stressful situation. The papers included in our study describe that people with dementia often use several strategies simultaneously. This is in line with the literature which report that more severe and acute stress situations demand the use of all available strategies and that people alternate between different strategies [11, 14-16]. Several papers convey how people with dementia keep going despite the rising challenges they meet due to progression of their cognitive and functional decline. In the early phase of the condition, many people have a strong will to continue living life as normal. This might be possible if one manages to mobilise available internal and external resources when approaching the specific situations [11]. Humour can be an effective coping strategy for making a threatening situation more harmless and thereby reducing stress. The experienced threats can vaporize if the person is able to make a joke and cover up the graveness of the situation. Through humour, the rational and sometimes harsh world can be kept stable as well as more tolerable [102]. Our study also showed that practical and emotional support are important coping resources for people with dementia. The findings are supported by a meta-synthesis of Eriksen et al. emphasising supportive interactions by family and friends as essential [23]. Supportive interactions enable people with dementia to prolong function and control in daily life, even though the areas of functioning gradually are becoming smaller. When symptoms increase and obstacles appear, our study gives the impression that most people with dementia fight the challenges. This is in line with a meta-synthesis conducted by Wolverson et al. [20] comprising the strengths that people can utilize in facing and fighting dementia, even leading to an experience of personal growth. Overall, fighting to keep going and overcome the daily struggles are signs of a problem-focused coping approach in people with dementia.

As the dementia condition progresses, and cognition as a personal coping resource declines, fighting the challenges will be more and more difficult. The person might experience that the ability to meet the situation changes and must therefore redefine what is important to him/her. Transformation in terms of new orientation and change of values (i.e. in relation to what is important in life), can be explained as response shift as described by Schwartz \& Sprangers [103]. By «letting go» people with dementia can make a psychological shift from trying to change the unchangeable to acceptance and thereby deal with the decline [104]. People with dementia adapt by adjusting and compensating for their losses and challenges by selecting other goals or fewer domains in which to optimize their efforts and thereby sustain identity, function, and autonomy $[105,106]$. In this process, emotion-focused strategies can help the person to adapt, reorient and regain balance. When balance is re-established, it may be relevant to use problem-focused strategies again.

Some of the studies refer to people with dementia expressing what they actually manage to do, despite their symptoms of decline. This can be seen as a particular way of understanding how values have been redefined. A recent meta synthesis showed that as the condition progresses, the lived space is narrowed for people with dementia. Førsund et al. [24] describe this process through the metaphor of the Russian "babushka doll," which is a set of dolls of decreasing sizes that all fit inside one another one by one. Step- by- step, the person with dementia faces new challenges in how to cope.

People with dementia experience many challenges and a lot of stress. When life changes and the condition progresses, finding ways to cope is essential for making everyday life work and solve practical tasks. However, coping is also about finding ways to continue being oneself and to experience meaning and autonomy [11]. Thus, knowledge about coping resources and strategies in people with dementia is essential in dementia care. This insight is highly relevant to health care personnel whose role it is to help facilitate a supportive environment for the person with dementia. However, the information is also highly relevant 
for informal carers. They may support the person's functioning by helping to facilitate and coordinate everyday living, but also by giving emotional and practical support. Though being able to do the things they still manage to do, perceptions of control continue to be a personal resource and may prevent experiences of helplessness and hopelessness, anxiety and depression [107].

\section{Limitations and strengths}

We performed a systematic meta-synthesis and a transparent description of the selection process for the included articles have been presented. However, we acknowledge that a complete overview is not attainable, despite our approaches. The value of both individual reviewers and the use of pairs of researchers to evaluate the studies should be accredited.

The CASP criteria for qualitative studies consist of ten questions in which we have chosen to the first nine. These nine criteria assess the quality of the structure and the objective elements of the articles. The last and 10th question has not been considered as this is a subjective appraisal of the value of the research and the particular article as a whole. The10th question can be seen as important for the external validity of single study as a whole. This said, in our review we used parts of the articles describing the experience of coping and we re-analyzed and synthesized the material. A broader description of context could have strengthened the review.

Only nine of 74 studies included in this meta-synthesis had a longitudinal design. Therefore, it was not possible to describe if - or how - coping strategies change over time due to progression of the dementia. Further research is recommended to use longitudinal design and explore to what degree the patients at different stages of the dementia trajectory, use either problem-focused and/ or emotional- focused coping strategies.

\section{Conclusions}

People with dementia experience stress during the dementia trajectory and it is essential to find ways to cope in order to make everyday life work and to continue being oneself and experience meaning and autonomy. Thus, knowledge about coping resources and strategies in people with dementia is essential in dementia care. The insight is highly relevant to health care personnel and next of kin whose role it is to help facilitate a supportive environment for the person with dementia. This systematic meta-synthesis shows that people with dementia cope in different ways and use several parallel strategies in order to meet the challenges they face. The comprehensive meaning is understood as: Balancing the struggle to live with dementia.

Further research should reconsider using a longitudinal design and explore coping strategies in different stages of the dementia trajectory. It is also interesting to explore the influence of coping resources like humour and social and emotional support on coping strategies and capabilities of people with dementia. Last, but not least it is important to explore the success of coping strategies in order to support these strategies in people with dementia.

\section{Abbreviations}

ASH: Anne Sofie Helvik; CASP: Critical appraisal skills programme; EKG: Ellen Karine Grov; EWT: Elisabeth Wiken Telenius; GHB: Guro Hanevold Bjørkløf; SE: Siren Eriksen; TIL: Tanja Louise Ibsen

\section{Acknowledgements}

We would like to thank university librarians Marit Gjone Sandsleth (University of South-east Norway) and Katarina Einarsen Enne and Vigdis Knutsen (Norwegian Advisory Unit on Aging and health) for providing essential help and advice for the computer-aided search.

\section{Authors' contributions}

All authors, GHB, ASH, TLI, EWT, EKG and SE, critically reviewed and analyzed the data. All the authors explored approximately one third of the potential articles and conducted the quality assessment of the articles and extracted the meaning units. TLI and SE further condensed the meaning units. ASH and GHB organized the material and labelled the meaning units with codes in order to organize the material. All authors compared codes, identified similarities and differences, and structured the codes into subcategories and categories. All authors were included in summarizing the text as one overall latent theme. SE and GBH wrote the article in cooperation with the other authors. All authors have read and approved the final manuscript.

\section{Funding}

The study, including systematic literature search, assessment of the quality of the studies, analysis, and interpretation of data; and writing the manuscript was all funded by the Norwegian Directorate of Health. However, the funding organization has not been involved in design, conducting the study or interpretation of results.

\section{Availability of data and materials}

All the articles included in this meta-synthesis are presented and accessible. The datasets used and analyzed during the current study are available from the corresponding author on reasonable request.

\section{Ethics approval and consent to participate}

Ethical approval and consent to participate has been gathered from the researchers responsible for each single study included in this meta-synthesis. As this is a literature review, ethical approval and consent to participate was not applicable.

\section{Consent for publication}

Not applicable.

\section{Competing interests}

The authors declare that they have no competing interests.

\section{Author details}

${ }^{1}$ Norwegian National Advisory Unit on Ageing and Health (Ageing and Health), Postbox 2136, N-3103 Tønsberg, Norway. ${ }^{2}$ Department of Public Health and General Practice, Norwegian University of Science and Technology, Trondheim, Norway. ${ }^{3}$ Department of Nursing and Health Promotion, Oslo Metropolitan University, Oslo, Norway. ${ }^{4}$ VID Spesialized University, Faculty of Health Studies, Oslo, Norway.

Received: 24 January 2019 Accepted: 7 October 2019

Published online: 30 October 2019

\section{References}

1. World Health Organization. Dementia; A public health priority. 2012. http:// www.who.int/mental_health/publications/dementia_report_2012/en/index. html. Accessed 15 Dec 2018.

2. Engedal K, Haugen P. Demens - sykdommer, diagnostikk og behandling Tønsberg: Forlaget aldring og helse - akademisk; 2018. [Norwegian] 
3. van der Steen J, Radbruch L, Hertogh CMPM, de Boer M, Hughes J, Larkin P, Francke $A L$, Jünger $S$, Gove $D$, Firth $P$, et al. White paper defining optimal palliative care in older people with dementia: a Delphi study and recommendations from the European Association for Palliative Care (EAPC). Palliat Med. 2014;28(3):197-209.

4. Livingston G, Sommerlad A, Orgeta V, Costafreda SG, Huntley J, Ames D, Ballard C, Banerjee S, Burns A, Cohen-Mansfield J, et al. Dementia intervention, prevention, and care. Lancet. 2017;390(10113):2673-734.

5. Alzheimer's Disease International. The Global Voice of Dementia https:// www.alz.co.uk/vision-and-aims. Accessed 15 Dec 2018.

6. World Health Organization. Global action plan on the public health response to dementia 2017-2025. 2017. http://apps.who.int/iris/bitstream/ handle/10665/259615/9789241513487-eng.pdf;jsessionid=961E40CEC2046 9345AD209F73642F2ED? sequence=1. Accessed 15 Dec 2018.

7. Norwegian Ministry of Health and Care Services. Dementiaplan 2020 -A more dementia friendly society. Edited by Norwegian Ministry of Health and Care Services. Oslo; 2015. [Norwegian]

8. Kitwood T. Dementia reconsidered: the person comes first. Buckingham: Open University Press; 1997.

9. Lazarus RS, Lazarus BN. Coping in coping with aging. New York: Oxford University Press; 2006. p. 53-79.

10. Folkman S. Personal contol and stress and coping processes:a theoretical analysis. J Pers Soc Psychol. 1984;46(4):839-52.

11. Folkman S, Lazarus R. An analysis of copingin in a middle-aged community sample. J Health Soc Behav. 1980;21:219-39.

12. Lasarus R, Folkman S. Stress, appraisal and coping. New York: Springer; 1984

13. de Ridder D, Kerssens J. Owing to the forrce of circumstances? The impact of situational fetatures and personal characteristics on coping patterns across situations. Psychol Health. 2003;18:217-36.

14. Aldwin C. Stress and Coping across the Lifespan. In: Folkman S, editor. The Oxford handbook of Stress, Health and Coping. Oxford, New York: Oxford University Press; 2011. p. 15-34.

15. Stroebe M. Coping with bereavement. In: Folkman S, editor. Oxford handbook of stress, health and coping. Oxford, New York: Oxford Univerity Press; 2011.

16. Stroebe $M$, Schut $H$. The dual process model of coping with bereavement: rationale and description. Death Stud. 1999;23(3):197-224.

17. Sørlie T, Sexton H. Predictors of the process of coping in surgical patients. Personal Individ Differ. 2001;30:947-60.

18. Sharp BK. Stress as experienced by people with dementia. An interpretative phenomenological analysis. Dementia. 2017;0:1-19.

19. van Vliet D, Persoon A, Bielderman A, Bakker C, Koopmans RTCM, Gerritsen DL, de Vugt ME. Feeling useful and engaged in daily life: exploring the experiences of people with young-onset dementia. Int Psychogeriatr. 2017;29(11):1889-98.

20. Wolverson EL, Clarke C, Moniz-Cook ED. Living positively with dementia: a systematic review and synthesis of the qualitative literature. Aging Ment Health. 2016;20(7):676-99.

21. Paterson B, Thorne S, Canam C, Jillings C. Meta-study of qualitative Health Research. A Practical Guide to Meta-Analysis and Meta-Synthesis. Thousand Oaks: Sage Publications; 2001

22. Zimmer L. Qualitative meta-synthesis: a question of dialoguing with texts. J Adv Nurs. 2006:53:311-8.

23. Eriksen S, Helvik A-S, Juvet L, Skovdahl K, Førsund L, Grov E. The experience of relations in people with dementia: a systematic Meta-synthesis. Dement Geriatr Cogn Disord. 2016;42:342-68.

24. Førsund L, Grov E, Helvik A, Juvet L, Skovdal K, Eriksen S. The experience of lived space in people with dementia: a systematic meta-synthesis. BMC Geriatr. 2018;18:33.

25. Shamseer L, Moher D, Clarke M, Ghersi D, Liberati A, Petticrew M, Shekelle P, Stewart L. Preferred reporting items for systematic review and meta-analysis protocols (PRISMA-P) 2015: elaboration and explanation. BMJ. 2015;350:g7647.

26. Critical Appraisal Skills Programme (CASP). Qualitative Research Checklist. In: Critical Appraisal Skills Programme (CASP); 2014. http://www.casp-uk.net/. Accessed 15 Dec 2018

27. Aldridge $H$, Fisher $P$, Laidlaw K. Experiences of shame for people with dementia: an interpretative phenomenological analysis. Dementia. 2017;0:1-16.

28. Aminzadeh F, Dalziel WB, Molnar FJ, Garcia LJ. Symbolic meaning of relocation to a residential care facility for people with dementia. Aging Ment Health. 2009;13(3):487-96.

29. Aminzadeh F, Dalziel WB, Molnar FJ, Garcia LJ. Meanings, functions, and experiences of living at home for individuals with dementia at the critical point of relocation. J Gerontol Nurs. 2010;36(6):28-35
30. Atta-Konadu E, Keller HH, Daly K. The food-related role shift experiences of spousal male care partners and their wives with dementia. J Aging Stud. 2011;25(3):305-15

31. Barrett C, Crameri P, Lambourne S, Latham JR, Whyte C. Understanding the experiences and needs of lesbian, gay, bisexual and trans Australians living with dementia, and their partners. Australas J Ageing. 2015;34(Suppl 2):34-8.

32. Beattie A, Daker-White G, Gilliard J, Means R. 'How can they tell?' a qualitative study of the views of younger people about their dementia and dementia care services. Health Soc Care Community. 2004;12(4):359-68.

33. Borley $G$, Hardy S. A qualitative study on becoming cared for in Alzheimer's disease: the effects to women's sense of identity. Aging Ment Health. 2017; 21(10):1017-22.

34. Bronner K, Perneczky R, McCabe R, Kurz A, Hamann J. Which medical and social decision topics are important after early diagnosis of Alzheimer's disease from the perspectives of people with Alzheimer's disease, spouses and professionals? BMC Res Notes. 2016;9(1):149

35. Brorsson A, Ohman A, Lundberg S, Nygard L. Accessibility in public space as perceived by people with Alzheimer's disease. Dementia. 2011; 10(4):587-602.

36. Chaplin R, Davidson I. What are the experiences of people with dementia in employment? Dementia. 2016:15(2):147-61.

37. Clare L, Rowlands J, Bruce E, Surr C, Downs M. The experience of living with dementia in residential care: an interpretive phenomenological analysis. The Gerontologist. 2008;48(6):711-20

38. Clemerson $\mathrm{G}$, Walsh $\mathrm{S}$, Isaac $\mathrm{C}$. Towards living well with young onset dementia: an exploration of coping from the perspective of those diagnosed. Dementia. 2014;13(4):451-66.

39. Dalby P, Sperlinger DJ, Boddington S. The lived experience of spirituality and dementia in older people living with mild to moderate dementia. Dementia. 2012;11(1):75-94.

40. Derksen E, Vernooij-Dassen M, Gillissen F, Rikkert MO, Scheltens P. Impact of diagnostic disclosure in dementia on patients and carers: qualitative case series analysis. Aging Ment Health. 2006;10(5):525-31.

41. de Witt L, Ploeg J, Black M. Living on the threshold: the spatial experience of living alone with dementia. Dementia. 2009;8(2):263-91.

42. de Witt L, Ploeg J, Black M. Living alone with dementia: an interpretive phenomenological study with older women. J Adv Nurs. 2010;66(8):1698-707.

43. Digby R, Moss C, MJ B. Trancferring from an acute hospital and settling into a subacutefacility:the experience of patients with dementia. Int J Older People Nursing. 2011;7:57-64.

44. Digby R, Bloomer MJ. People with dementia and the hospital environment: the view of patients and family carers. Int J Older People Nursing. 2012;9(1):34-43.

45. Duggan S, Blackman T, Martyr A, Van Schaik P. Impact of early dementia on outdoor life: a 'shrinking world'? Dementia. 2008;7(2):191-204.

46. Fleming R, Kelly F, Stillfried G. 'I want to feel at home': establishing what aspects of environmental design are important to people with dementia nearing the end of life. BMC Palliat Care. 2015;14:26.

47. Frazer SM, Oyebode JR, Cleary A. How older women who live alone with dementia make sense of their experiences: an interpretative phenomenological analysis. Dementia. 2011;11(5):677-93.

48. Genoe MR, Dupuis SL, Keller HH, Martin LS, Cassolato C, Edward HG. Honouring identity through mealtimes in families living with dementia. J Aging Stud. 2010;24(3):181-93.

49. Genoe MR, Keller HH, Martin LS, Dupuis SL, Reimer H, Cassolato C, Edward G. Adjusting to mealtime change within the context of dementia. Can J Aging. 2012;31(2):173-94.

50. Genoe MR, Dupuis SL. The role of leisure within the dementia context. Dementia. 2014;13(1):33-58.

51. Gill L, White L, Cameron ID. Interaction in community-based aged healthcare: perceptions of people with dementia. Dementia. 2011;10(4):539-54.

52. Gilmour JA, Huntington AD. Finding the balance: living with memory loss. Int J Nurs Pract. 2005:11(3):118-24.

53. Goodman C, Amador S, Elmore N, Machen I, Mathie E. Preferences and priorities for ongoing and end-of-life care: a qualitative study of older people with dementia resident in care homes. Int J Nurs Stud. 2013;50(12): 1639-47.

54. Hain D, Touhy TA, Compton Sparks D, Engström G. Using narratives of individuals and couples living with early stage dementia to guide practice. J Nurs Pract Appl Rev Res. 2014;4(2):82-93.

55. Harman G, Clare L. Illness representations and lived experience in earlystage dementia. Qual Health Res. 2006;16(4):484-502. 
56. Harris PB. Maintaining friendships in early stage dementia: factors to consider. Dementia. 2011;11(3):305-14.

57. Hedman R, Hansebo G, Ternestedt B-M, Hellström I, Norberg A. How people with Alzheimer's disease express their sense of self: analysis using rom Harré's theory of selfhood. Dementia. 2013;12(6):713-33.

58. Hedman R, Hansebo G, Ternestedt BM, Hellström I, Norberg A. Expressed sense of self by people with Alzheimer's disease in a support group interpreted in terms of agency and communion. J Appl Gerontol. 2016;34(4):421-43.

59. Heggestad AK, Nortvedt P, Slettebo A. 'Like a prison without bars': dementia and experiences of dignity. Nurs Ethics. 2013;20(8):881-92.

60. Hellstrom I, Eriksson H, Sandberg J. Chores and sense of self: gendered understandings of voices of older married women with dementia. Int J Older People Nursing. 2015;10(2):127-35.

61. Herron R, Rosenberg M. "Not there yet": examining community support from the perspective of people with dementia and their partners in care. Soc Sci Med. 2017;173:81-7.

62. Hillman A, Jones IR, Quinn C, MNelis S, Clare L. Dualities of dementia illness narratives and their role in a narrative economy. Soc Health Illness. 2018; 40(5):874-91.

63. Hulko W. From 'not a big deal' to 'hellish': experiences of older people with dementia. J Aging Stud. 2009;23(3):131-44.

64. Johannessen A, Moller A. Experiences of people with early-onset dementia in everyday life: a qualitative study. Dementia. 2011;12(4):410-24.

65. Johannessen A, Moller A, Haugen PK, Biong S. A shifting sense of being: a secondary analysis and comparison of two qualitative studies on youngonset dementia. Int J Qual Stud Health Well-being. 2014;9:24756.

66. Karlsson E, Sävenstedt S, Axelsson K, Zingmark K. Stories about life narrated by people with Alzheimer's disease. J Adv Nurs. 2014;70(12):2791-2799 2799.

67. Keller HH, Martin LS, Dupuis S, Genoe R, Edward HG, Cassolato C. Mealtimes and being connected in the community-based dementia context. Dementia. 2010;9(2):191-213.

68. Langdon SA, Eagle A, Warner J. Making sense of dementia in the social world: a qualitative study. Soc Sci Med. 2007;64(4):989-1000.

69. Lawrence V, Murray J, Ffytche D, Banerjee S. "Out of sight, out of mind": a qualitative study of visual impairment and dementia from three perspectives. Int Psychogeriatr. 2009;21(3):511-8.

70. Lee SM, Roen K, Thornton A. The psychological impact of a diagnosis of Alzheimer's disease. Dementia. 2014;13(3):289-305.

71. MacKinlay E. Using spiritual reminiscence with a small group of Latvian residents with dementia in a nursing home: a multifaith and multicultural perspective. J Relig Spiritual Aging. 2009;21(4):318-29.

72. MacRae H. Self and other: the importance of social interaction and social relationships in shaping the experience of early-stage Alzheimer's disease. J Aging Stud. 2011;25(4):445-56.

73. Mazaheri M, Eriksson LE, Heikkilä K, Nasrabadi AN, Ekman S-L, Sunvisson H. Experiences of living with dementia: qualitative content analysis of semistructured interviews. J Clin Nurs. 2013;22(21/22):3032-41.

74. Merrick K, Camic PM, O'Shaughnessy M. Couples constructing their experiences of dementia: a relational perspective. Dementia. 2016;15(1):34-50.

75. Mjørud M, Engedal K, Røsvik J, Kirkevold M. Living with dementia in a nursing home, as described by people with dementia: a phenomenological hermeneutic study. BMC Health Serv Res. 2017;17(1):93.

76. Molyneaux V, Butchard S, Simpson J, Murray C. The co-construction of couplehood in dementia. Dementia. 2011;11(4):483-502.

77. Mushi D, Rongai A, Paddick SM, Dotchin C, Mtuya C, Walker R. Social representation and practices related to dementia in Hai District of Tanzania. BMC Public Health. 2014;14:260.

78. Nowell ZC, Thornton A, Simpson J. The subjective experience of personhood in dementia care settings. Dementia. 2013;12(4):394-409.

79. Nygard L. Meaning of everyday technology as experienced by people with dementia who live alone. Dementia. 2008;7(4):481-502.

80. Pesonen HM, Remes AM, Isola A. Diagnosis of dementia as a turning point among Finnish families: a qualitative study. Nurs Health Sci. 2013;15(4):489-96.

81. Phinney A, Moody EM. Leisure connections: benefits and challenges of participating in a social recreation Group for People with Early Dementia. Act Adapt Aging. 2011;35(2):111-30

82. Pipon-Young FE, Lee KM, Jones F, Guss R. I'm not all gone, I can still speak: the experiences of younger people with dementia. An action research study. Dementia. 2012;11(5):597-616.

83. Read ST, Toye C, Wynaden D. Experiences and expectations of living with dementia: a qualitative study. Collegian. 2017;24(5):427-32.
84. Roach P, Drummond N, Keady J. Nobody would say that it is Alzheimer's or dementia at this age': family adjustment following a diagnosis of earlyonset dementia. J Aging Stud. 2016;36:26-32.

85. Rostad D, Hellzen O, Enmarker I. The meaning of being young with dementia and living at home. Nurs Rep. 2013;3(1):12-7.

86. Sandberg $L$, Rosenberg L, Sandman P-O, Borell L. Risks in situations that are experienced as unfamiliar and confusing-the perspective of people with dementia. Dementia. 2017;16(4):471-85.

87. Sixsmith A, Gibson G. Music and the wellbeing of people with dementia. Ageing Soc. 2007;27(1):127-45.

88. Stephan A, Bieber A, Hopper L, Joyce R, Irving K, Zanetti O, Portolani E, Kerpershoek L, Verhey $F$, de Vugt $M$, et al. Barriers and facilitators to the access to and use of formal dementia care: findings of a focus group study with people with dementia, informal carers and health and social care professionals in eight European countries. BMC Geriatr. 2018;18(1):131.

89. Svanstrom R, Sundler AJ. Gradually losing one's foothold: a fragmented existence when living alone with dementia. Dementia. 2015;14(2):145-63.

90. Tak SH, Kedia S, Tongumpun TM, Hong SH. Activity Engagement: Perspectives from Nursing Home Residents with Dementia. Educ Gerontol. 2015;41(3):182-192 111.

91. Tolhurst $E$, Weicht B. Preserving personhood. The strategies of men negotiating the experience of dementia. J Aging Stud. 2017:40:29-35.

92. Thein NW, D'Souza G, Sheehan B. Expectations and experience of moving to a care home: perceptions of older people with dementia. Dementia. 2011;10(1):7-18

93. van Zadelhoff E, Verbeek H, Widdershoven G, van Rossum E, Abma T. Good care in group home living for people with dementia. Experiences of residents, family and nursing staff. J Clin Nurs. 2011;20(17-18):2490-500.

94. Vernooij-Dassen M, Derksen E, Scheltens P, Moniz-Cook E. Receiving a diagnosis of dementia: the experience over time. Dementia. 2006:5(3):397-410.

95. Vikstrom S, Josephsson S, Stigsdotter-Neely A, Nygård L. Engagement in activities: experiences of people with dementia and their caregiving spouses. Dementia. 2008;7(2):251-70.

96. Weaks DOT, Wilkinson H, McLeod J. Daring to tell: the importance of telling others about a diagnosis of dementia. Ageing Soc. 2015;35(4):765-84.

97. Wolverson EL, Clarke C, Moniz-Cook E. Remaining hopeful in early-stage dementia: a qualitative study. Aging Ment Health. 2010;14(4):450-60.

98. Öhman A, Nygård L. Meanings and motives for engagement in self-chosen daily life occupations among individuals with Alzheimer's disease. OTJR. 2005;25(3):89-97.

99. Dixon-Woods M, Agarwal S, Jones D, Young B, Sutton A. Synthesising qualitative and quantitative evidence: a review of possible methods. Health Serv Res Policy. 2005;10:45-53.

100. Eilertsen G, Ormstad H, Kirkevold M. Experiences of poststroke fatigue: a qualitative meta-synthesis. J Adv Nurs. 2013;69(3):514-25.

101. Graneheim U, Lundman B. Qualitative content analysis in nursing research: concepts, procedures and measures to achieve trustworthiness. Nurse Educ Today. 2004;24(2):105-12.

102. Svebak S. A theory of sense of humor. Scand J Psychol. 1974;15(1):99-107 https://onlinelibrary.wiley.com/doi/abs/10.1111/j.1467-9450.1974.tb00561.x.

103. Schwartz C, Sprangers M. Methodological approaches for assessing response shift in longitudinal health-related quality-of-life research. Soc Sci Med. 1999:48:1531-48.

104. Dunne E, Wrosch C, Miller G. Goal disengagement, functional disability, and depressive symptoms in old age. Health Psychol. 2011;30(6):763-70.

105. Baltes P, Baltes M. Psychological perspective on successful aging: the model of selective optimization with compensation. Cambridge: Cambridge University Press; 1990.

106. Wrosch C. Self-regulation of Unattaineable Goals and Pathways to quality of life. In: Folkman S, editor. The Oxford Handbook of Stress, Health, and Coping. Oxford: Oxford University Press; 2011. p. 319-33.

107. Skinner EA, Zimmer-Gembeck MJ. Perceived control and the development of coping. In: Folkman S, editor. The Oxford handbook of stress, health, and coping. Oxford: Oxford University Press; 2011. p. 35-59. https://doi.org/10. 1093/oxfordhb/9780195375343.013.0003.

\section{Publisher's Note}

Springer Nature remains neutral with regard to jurisdictional claims in published maps and institutional affiliations. 